\title{
Mapping Potentially Acid Generating Material on Abandoned Mine Lands Using Remotely Piloted Aerial Systems
}

\author{
Alison S. Cramer ${ }^{1, *}$, Wendy M. Calvin ${ }^{1, *}$, Scott W. McCoy ${ }^{1}$, Ronald J. Breitmeyer ${ }^{2}$, Marja Haagsma ${ }^{3}$ \\ and Christopher Kratt ${ }^{4}$ \\ 1 Department of Geological Sciences and Engineering, University of Nevada, Reno, NV 89557, USA; \\ scottmccoy@unr.edu \\ 2 Montana Bureau of Mines and Geology, Butte, MT 59101-6011, USA; rbreitmeyer@mtech.edu \\ 3 Department of Biological and Ecological Engineering, Oregon State University, Corvallis, OR 97331, USA; \\ haagsmam@oregonstate.edu \\ 4 Center for Transformative Environmental Monitoring Programs (CTEMPs), Department of Geological \\ Sciences and Engineering, University of Nevada, Reno, NV 89557, USA; krattc@unr.edu \\ * Correspondence: alisoncramer@nevada.unr.edu (A.S.C.); wcalvin@unr.edu (W.M.C.)
}

check for updates

Citation: Cramer, A.S.; Calvin, W.M.; McCoy, S.W.; Breitmeyer, R.J.; Haagsma, M.; Kratt, C. Mapping Potentially Acid Generating Material on Abandoned Mine Lands Using Remotely Piloted Aerial Systems. Minerals 2021, 11, 365. https:// doi.org/10.3390/min11040365

Academic Editor: Konstantinos G Nikolakopoulos and Christian Mielke

Received: 31 January 2021

Accepted: 23 March 2021

Published: 31 March 2021

Publisher's Note: MDPI stays neutral with regard to jurisdictional claims in published maps and institutional affiliations.

Copyright: (c) 2021 by the authors. Licensee MDPI, Basel, Switzerland. This article is an open access article distributed under the terms and conditions of the Creative Commons Attribution (CC BY) license (https:/ / creativecommons.org/licenses/by/ $4.0 /)$.

\begin{abstract}
Weathering and transport of potentially acid generating material (PAGM) at abandoned mines can degrade downstream environments and contaminate water resources. Monitoring the thousands of abandoned mine lands (AMLs) for exposed PAGM using field surveys is time intensive. Here, we explore the use of Remotely Piloted Aerial Systems (RPASs) as a complementary remote sensing platform to map the spatial and temporal changes of PAGM across a mine waste rock pile on an AML. We focus on testing the ability of established supervised and unsupervised classification algorithms to map PAGM on imagery with very high spatial resolution, but low spectral sampling. At the Perry Canyon, NV, USA AML, we carried out six flights over a 29-month period, using a RPAS equipped with a 5-band multispectral sensor measuring in the visible to near infrared (400-1000 nm). We built six different $3 \mathrm{~cm}$ resolution orthorectified reflectance maps, and our tests using supervised and unsupervised classifications revealed benefits to each approach. Supervised classification schemes allowed accurate mapping of classes that lacked published spectral libraries, such as acid mine drainage (AMD) and efflorescent mineral salts (EMS). The unsupervised method produced similar maps of PAGM, as compared to supervised schemes, but with little user input. Our classified multi-temporal maps, validated with multiple field and lab-based methods, revealed persistent and slowly growing 'hotspots' of jarosite on the mine waste rock pile, whereas EMS exhibit more rapid fluctuations in extent. The mapping methods we detail for a RPAS carrying a broadband multispectral sensor can be applied extensively to AMLs. Our methods show promise to increase the spatial and temporal coverage of accurate maps critical for environmental monitoring and reclamation efforts over AMLs.
\end{abstract}

Keywords: remotely piloted aerial systems; acid mine drainage; remote sensing; multispectral; hyperspectral; jarosite; iron oxides

\section{Introduction}

Abandoned Mine Lands (AMLs) can adversely impact the environmental quality of watersheds in various ways. When sulfide minerals, such as pyrite, are brought to the surface during mining, they can react with air and water. Sulfuric acid and ferrous iron can form to create acid mine drainage (AMD), which can contaminate nearby surface and groundwater. If AMLs and their associated waste rock piles are continually exposed to weathering, large concentrations of sulfates and heavy metals can be found in surface and groundwater for decades after mining has ceased [1,2].

Containment strategies for mine waste rock or other solid mining wastes, include capping the waste rock with a soil or engineered cover. These can avert exposure and erosion of 
potentially acid generating material (PAGM) and prevent precipitation from infiltrating into the mine waste material, which can speed up chemical reactions [3]. When these cover systems remain intact, and are properly designed and maintained, they are effective at reducing infiltration resulting in AMD formation and the subsequent transport of PAGM [4-6]. Owing to environmental exposure, however, erosion of cover material or mine waste can occur, increasing the likelihood of the formation and exposure of AMD and PAGM. If PAGM is exposed at the surface, large rainfall runoff events can transport PAGM, often accompanied by heavy metals, into downstream environments $[7,8]$.

Systematic monitoring of AMLs, particularly surface exposure of PAGM or AMD dispersion, can reveal compromised containment systems and identify high-priority sites in need of remediation. Current monitoring techniques on AMLs commonly rely on in-person field measurements [9], making it difficult to map PAGM exposure and AMD dispersion through time, especially across large spatial scales and at high temporal resolution. Additionally, remote AMLs with limited access can make ground measurements unfeasible [10]. As a result, many AMLs go without monitoring for years at a time.

New advances in remote sensing, such as remotely piloted aerial systems (RPASs) equipped with multispectral sensors, can provide a complementary substitute for ground measurements. These systems show promise in reducing the time and personnel required to map the temporal dispersion of AMD and PAGM at high temporal resolution and across large spatial scales. Such maps are critical to assess the stability and effectiveness of AML containment and to identify high-priority remediation projects. RPASs have been used to monitor and quantify change in open pit mines [11,12], but haven't been widely implemented to monitor AMLs. Several studies have successfully used remote sensing techniques with hyperspectral aerial or satellite imagery [13-16] to classify minerals and map acidic mine waste. However, high resolution multispectral aerial imagery is only available for a few AML locations. Additionally, the coarse spatial resolution of multispectral satellite imagery, $20 \mathrm{~m}$ or more, cannot be used to map $\mathrm{cm}$ or m-scale features of interest. These include both the dispersion of AMD from small mine seeps and patches of PAGM on mine waste rock piles. Orthorectified reflectance maps with $\mathrm{cm}$-scale resolution, provide an alternative approach to acquire the needed imagery to efficiently monitor AMD and PAGM on AMLs in small watersheds. Low-flying RPASs can solve the spatial resolution problem with reflectance maps, typically acquired at $\mathrm{cm}$ to $\mathrm{dm}$ resolution. However, the broadband multispectral sensors that are commonly flown on RPASs have limited spectral resolution. This raises the question, how accurately and by what classification algorithm can PAGM or AMD be mapped when using this unique combination of high spatial resolution and relatively low spectral sampling?

We addressed AML monitoring challenges by conducting a case study at the Perry Canyon, NV AML, using a 5-band multispectral sensor deployed on an RPAS. We carried out six flights over a 29-month period using an RPAS equipped with a 5-band multispectral sensor measuring in the visible to near infrared $(400-1000 \mathrm{~nm})$. Our primary objectives were to test the ability of established supervised and unsupervised pixel classification algorithms to map PAGM from this imagery and then to quantify change in PAGM and AMD through time. We begin with a brief overview of the site and then describe the classification methods that are widely used in remote sensing applications, but have yet to be evaluated to map PAGM from high-resolution multispectral imagery. We validated the maps through pixel classification accuracy assessments, field data collection, and sample analysis. We present our classified maps of AMD and yellow and red soils (PAGM) and document their temporal change at the Perry Canyon AML. We finish with a discussion and an outline for best practices when mapping PAGM and AMD using a RPAS equipped with a 5-band multispectral sensor.

\section{Field Site}

The Perry Canyon AML is part of the Pyramid Mining District in Washoe County Nevada, USA [17] and is located in a narrow, steep canyon in the northern Pah Rah Range 
(Figure 1). Perry Canyon hosts a system of historical mines, some of which are adjacent to Perry Creek (Figure 1b), an ephemeral creek with multiple springs and mine water seeps. Mining in Perry Canyon began in the late 1800's. The Jones-Kincaid mine, our primary focus, was developed in the 1870's, with the main commodities being silver and copper [18]. The mine consisted of a $300 \mathrm{~m}$ adit, $150 \mathrm{~m}$ deep shaft, and a mine waste rock pile (Figure 1b) [18].

We chose to monitor AMD and PAGM at the Perry Canyon AML because it is a site with problems characteristic of those present at many of the thousands of waste rock piles and adits in the Western United States [19] (Figure 1a). It has been established by the Bureau of Land Management (BLM) and the University of Nevada, Reno as an important site for testing and evaluating various monitoring, evaluation, and treatment methods for AMLs [20-22]. In 1995, BLM and the Nevada Bureau of Mines and Geology (NBMG) identified the Jones-Kincaid Mine and the associated mine waste rock pile (Figure 1b), as being potentially hazardous due to the presence of AMD [23]. Specifically, waters draining from the abandoned mine were among the most acidic in the state, with elevated levels of toxic metal concentrations 2300 times the Federal safe drinking water standard [23,24]. The 2004 Final Perry Canyon Site Investigation Report [17] confirmed the presence of AMD flowing from the adit seep at the Jones-Kincaid mine waste rock pile. Efflorescent mineral salts (EMS) sampled at the adit seep and downstream of the waste rock, contained various concentrations of heavy metals [17]. Samples from the mine waste rock pile revealed sulfate concentrations greater than $8000 \mathrm{mg} \mathrm{L}^{-1}$ and various metal leachate concentrations, with the most elevated being copper, zinc, and iron. The acid generating potential was greater than $100 \mathrm{t} \mathrm{CaCO}_{3} \mathrm{Kt}^{-1}$, with no acid neutralization potential detected [17].
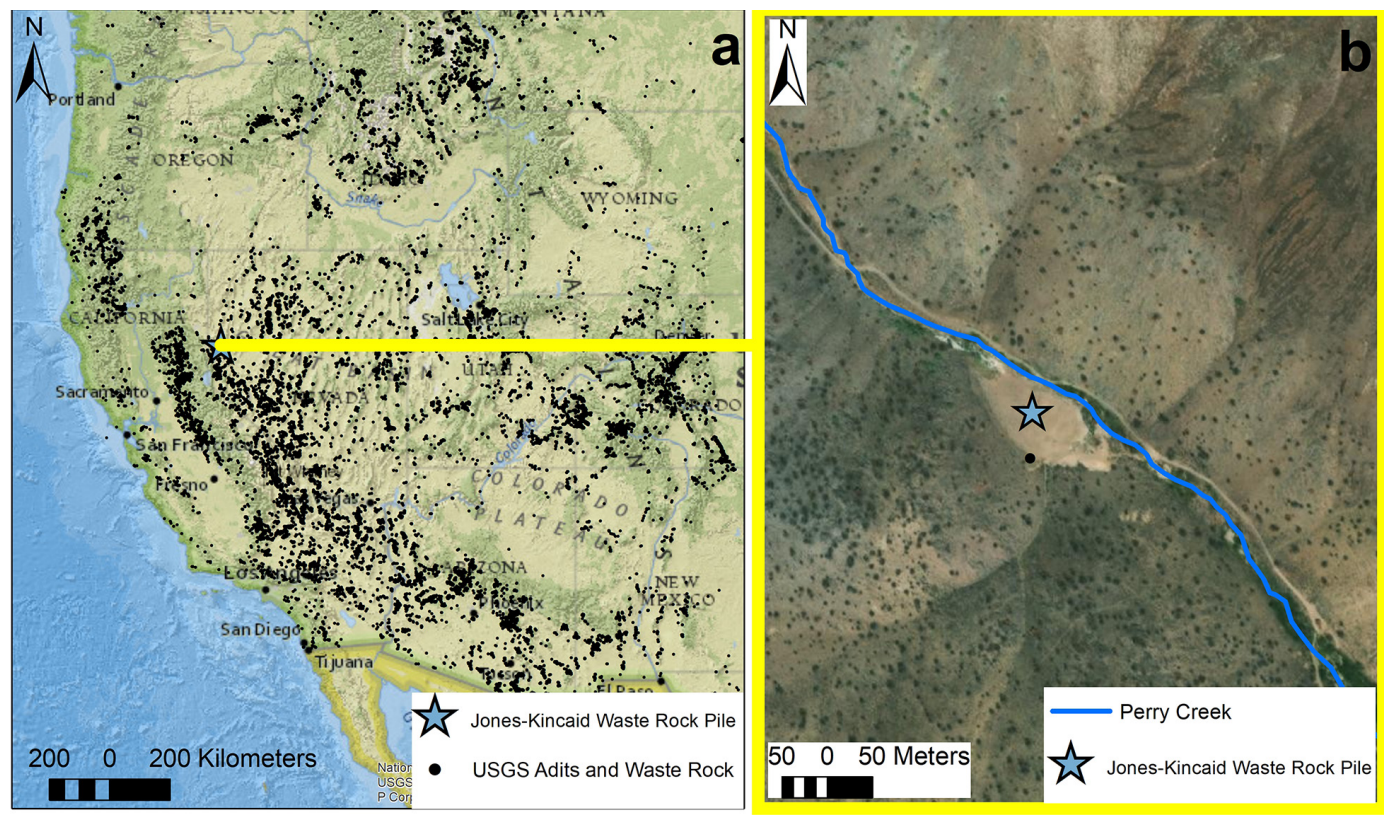

Figure 1. (a) Map of abandoned adits and waste rock piles, highlighitng the extent of inactive and active mine inventory in the Western U.S. [19]; The Jones-Kincaid Waste Rock Pile in Perry Canyon, NV is indicated using a blue star. (b) Jones-Kincaid Waste Rock study area and adjacent Perry Creek.

In September 2006, the Universal Environmental Nevada (UEN) consultants completed the remediation activities on the Jones-Kincaid mine waste rock pile [25]. The completed remediation included capturing the mine waters to redirect them away from the waste pile via a drainage pipe and adit backfilling, re-contouring and capping of the waste pile, and seeding for re-vegetation of disturbed areas [25]. An approximately $7 \mathrm{~cm}$ thick soil cover was applied over the mine waste rock to limit erosion of waste rock, infiltration, and AMD formation via leaching $[17,25]$. Despite the completed remediation, seasonal AMD discharge continues, and EMS still form at various locations across the site. Erosion of the Jones-Kincaid waste rock cover has occurred since its installation [20], exposing 
'hotspots' of yellow and red soil, and red coated minerals. Previous site characterization data, summarized below in the section on field validation activities, indicate that these 'hotspots' are secondary sulfate minerals, including jarosite, and iron oxide rich soils. All together these site characteristics and previous work make for a unique opportunity to test the efficacy of mapping and classifying AMD and PAGM with a broadband sensor atop a RPAS, using common remote sensing techniques.

\section{Materials and Methods}

We mapped the temporal change of PAGM on the Jones-Kincaid mine waste rock pile with reflectance maps, and three remote sensing techniques. To collect needed imagery, we deployed a lightweight 5-band multispectral sensor (450-850 nm) via RPAS, in six flights over 29 months. We tested multiple classification methods to identify surface materials of interest, including Maximum Likelihood (ML), Spectral Angle Mapper (SAM), and Band Math Ratios (BMRs). To validate the remote mapping along select transects, we (1) collected soil samples and analyzed them for general soil chemistry and mineral identification using XRD, (2) imaged the transects at mm-resolution with a hyperspectral sensor (400-1000 nm) on a custom-built motion-control system, (3) collected high resolution in silico field spectra with a hand held spectrometer (350-2500 nm).

\subsection{Mapping Targets and Key Indicators of Potentially Acid Generating Material}

Our study focused on classifying, mapping, and validating surface materials and AMD on the Jones-Kincaid mine waste rock pile. The surface materials included yellow soil (jarosite), white and blue soil (EMS), and red soils (iron oxides and other secondary iron rich coatings indicative of AMD). Yellow mine-rich soils are typically associated with jarosite [26], a secondary iron-bearing sulfate mineral which forms under acidic conditions. Jarosite has been used in many studies of active and inactive mines to locate areas of PAGM [16,26,27]. Red soils are typically associated with iron oxides (ferric oxides), and have the ability to sequester heavy metals and generate more acidic water [28,29]. Iron rich minerals have unique and identifiable spectral reflectance signatures in the visible to near-infrared (VNIR) [16], making them good candidates to identify areas of PAGM for this study. Jarosite has an absorption feature at approximately $450 \mathrm{~nm}$ and a downturn at $700 \mathrm{~nm}$ [30], and iron oxides have an upturn with a steep slope from 550 to $700 \mathrm{~nm}$ [31].

\subsection{RPAS Surveys: Micasense 5-Band Multispectral Sensor}

To map the temporal dispersion of AMD discharge into Perry Creek, and the time variable distribution of jarosite and iron oxides at the Jones-Kincaid mine waste rock pile, we used a Tarot 650 RPAS equipped with a 5-Band MicaSense RedEdge sensor. The five bands ranged in wavelengths from 475 to $840 \mathrm{~nm}$ (Table 1). We surveyed over a 29-month period, and survey dates included June 2018, September 2018, November 2018, March 2019, July 2019, and October 2020. Universal Ground Control Station (UGCS), version 3.0.1302 software (SPH Engineering, Riga, Latvia), was used to plan and execute programmed missions, flown at $80 \mathrm{~m}$ above ground level (AGL) with $80 \%$ front and side overlap. The missions were flown with a flight speed of $5 \mathrm{~m} \mathrm{~s}^{-1}$ with an orientation parallel to topographic contours. GPS measurements were recorded with a Trimble RTX R10 receiver (Trimble Inc., Sunnyvale, CA, USA) with better than $5 \mathrm{~cm}$ vertical accuracy. Up to 15 Ground Control Points (GCPs) were established that covered both the canyon bottom and slope up to the ridge line. For surveys which covered only the canyon bottom, approximately eight GCPs were necessary for accurate registration. The analysis presented herein focused on subsets of each time series that match the June 18 survey, which encompassed the canyon bottom and waste rock pile. Sensor specifications are shown in Table 2.

We aligned the visual images obtained during the RPAS flights using Structure from Motion (SfM) in Pix4D v.3.2 (Pix4D, Lausanne, Switzerland) [32]. Geometry of the scene, camera positions, and orientation were solved simultaneously using an iterative bundle adjustment procedure to align overlapping images based on the automatic extraction of 
features [33]. We manually identified GCPs on multiple images within each survey, which enabled an assessment of any non-linear structural errors in the SfM reconstruction. We used the aligned images to produce digital surface models (DSMs). From here, built-in software functionality converted raw data to reflectance by taking advantage of white reference calibration panel images taken in the field during each survey and measurements from a Downwelling Light Sensor (DLS) mounted on top of the drone. DLS data were recorded in the header file of each image. Utliizing the DSMs and reflectance calibration, we created reflectance maps for each band and each survey, where the value of each pixel indicates the reflectance of the object. Reflectance maps for each band were combined into a single file in ascending band order, from Blue to NIR (Figure 2), for each survey period. Processing details for each flight are presented in Table 3.

Table 1. Micasense 5-band multispectral sensor wavelengths.

\begin{tabular}{ccc}
\hline Spectral Bands & Wavelength $(\mathbf{n m})$ & Bandwidth $(\mathbf{n m})$ \\
\hline Blue & 475 & 20 \\
Green & 560 & 20 \\
Red & 668 & 20 \\
Red Edge & 717 & 10 \\
Near-Infrared (NIR) & 850 & 40 \\
\hline
\end{tabular}

Table 2. Micasense 5-band multispectral sensor specifications.

\begin{tabular}{cccc}
\hline Sensor & Sensor Dimensions (mm) & Focal Length (mm) & Shutter Type \\
\hline Micasense 5-Band Multispectral Sensor & $4.8 \times 3.6$ & 5.5 & Rolling \\
\hline
\end{tabular}

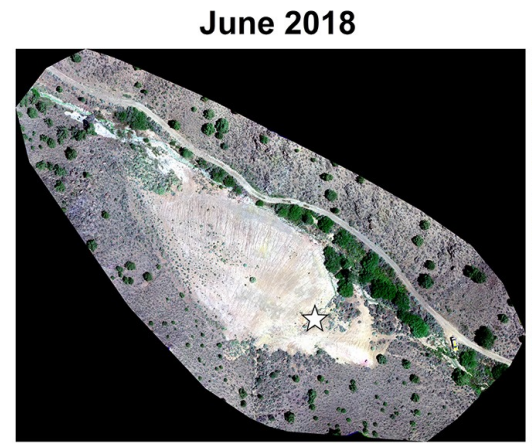

March 2019

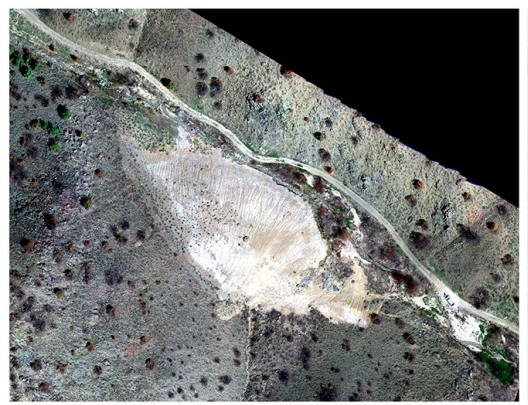

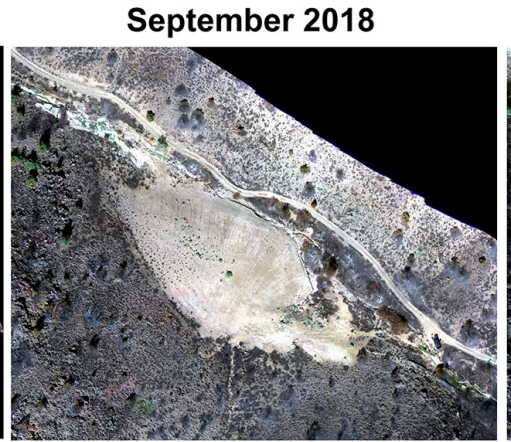

July 2019

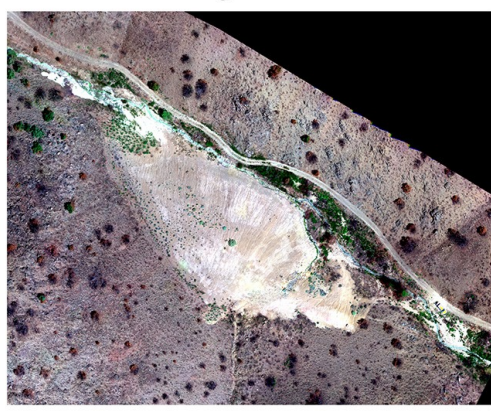

November 2018

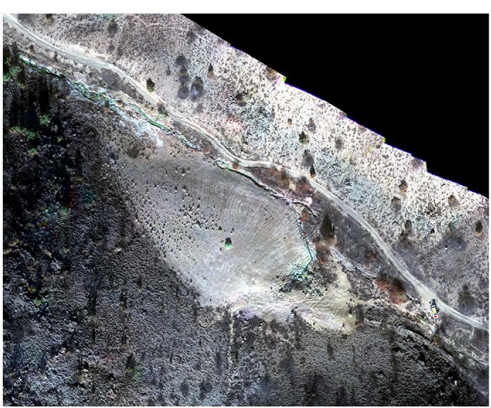

October 2020

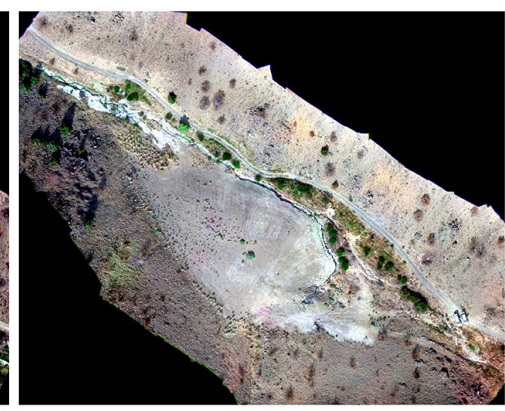

Figure 2. Approximate true color reflectance maps using MicaSense channels centered on 668, 560, and $475 \mathrm{~nm}$. North is up in each image. The scene is $240 \mathrm{~m}$ wide and $184 \mathrm{~m}$ tall. The adit drain is near the southeast corner of the waste rock pile, indicated with a star on the June 18 image. 
Table 3. Pix4D structure from motion processing details and results for the orthorectified reflectance maps.

\begin{tabular}{ccccccc}
\hline Survey Date & Area $\left.\mathbf{( k m}^{2}\right)$ & GSD $(\mathbf{c m})$ & GCPs & MRE (Pixels) & Images Calibrated & Resolution $(\mathbf{c m})$ \\
\hline June 2018 & 0.025 & 2.9 & 8 & 0.024 & $1180 / 1180$ & 2.9 \\
September 2018 & 0.2 & 3.63 & 15 & 0.038 & $5815 / 6238$ & 3.63 \\
November 2018 & 0.149 & 3.79 & 11 & 0.029 & $6320 / 6785$ & 3.79 \\
March 2019 & 0.19 & 3.5 & 14 & 0.125 & $7375 / 8060$ & 3.5 \\
July 2019 & 0.159 & 3.78 & 14 & 0.361 & $5445 / 5690$ & 3.78 \\
October 2020 & 0.031 & 2.71 & 8 & 0.161 & $3560 / 3651$ & 2.71 \\
\hline
\end{tabular}

Abbreviations: GSD = ground sampling distance, GCPs = ground control points, MRE = mean reprojection error.

\subsection{Nano-Hyperspectral 271-Band Sensor Transects}

Hyperspectral data were acquired on 9 October 2018, during cloud-free conditions. Based on field inspection of the waste pile cover we picked four transects to sample a wide range of surface types. Transect 1 and 2 were just downstream from the adit (Figure 3). Transect 3 was at a higher elevation on the center of the waste pile and Transect 4 was at the far western end (Figure 3). We used a Nano VNIR Hyperspec camera from Headwall Photonics, MA, USA, which measured reflected light in the 400-1000 nm region. The camera was fitted with an $8 \mathrm{~mm}$ lens with a 30.4 degree field of view (FOV). It captured data in 271 bands with 12-bit radiometric resolution with a full width half maximum (FWHM) of $6 \mathrm{~nm}$. The camera was a push broom sensor, thus in order to acquire spatial data, the camera needed to be moved in a smooth and controlled manner. Therefore, data were captured using a custom-built motioncontrol system [34] (Figure 3a) that points the instrument at nadir with an above ground height of $2.5 \mathrm{~m}$. The exposure time was set such that the camera did not get oversaturated while imaging the 99\%-reflectance standard (Labsphere Inc., North Sutton, NH, USA). The velocity of the camera moving on the system is a function of the distance between the camera and the ground (height) and the frame rate. The velocity and frame rate were chosen such that the resulting pixels of the image were square. The resulting images were $1.3 \mathrm{~m}$ wide, $5.5 \mathrm{~m}$ long, with a pixel scale of $2 \mathrm{~mm}$ (Figure 3, Transects 1-4). Raw data were converted to radiance in SpectralView (version 5.5.1., Headwall Photonics, MA, USA) using both a dark reference image to account for background noise and the sensor-specific calibration. Next, we converted the radiance to reflectance using the reflectance standard and the empirical line method [35]. We used five to six GCPs per transect, and GPS measurements were recorded with the same Trimble RTX R10 receiver used in the RPAS surveys. The reflectance cubes were then orthorectified in Arcmap 10.5.1 (ArcGIS, ESRI Inc, Redlands, CA, USA) with a first order polynomial fit and nearest-neighbor resampling. The final image cube was a $2 \mathrm{~mm}$ per pixel reflectance map (Figure 3, Transects 1-4).

In order to improve the signal-to-noise ratio of the hyperspectral data, we re-sampled the 271 band data to 45 bands using a spectral binning algorithm that averages 5 spectral channels into one bin (Figure 4). This reduced the FWHM but did not impact our ability to map the AMD materials of interest. We truncated the spectra at $850 \mathrm{~nm}$, such that the final spectra also matched the wavelengths of the 5-band MicaSense multispectral sensor. For the validation hyperspectral transect data, given the larger number of channels and better definition of spectral shape, we used spectral angle mapper. 


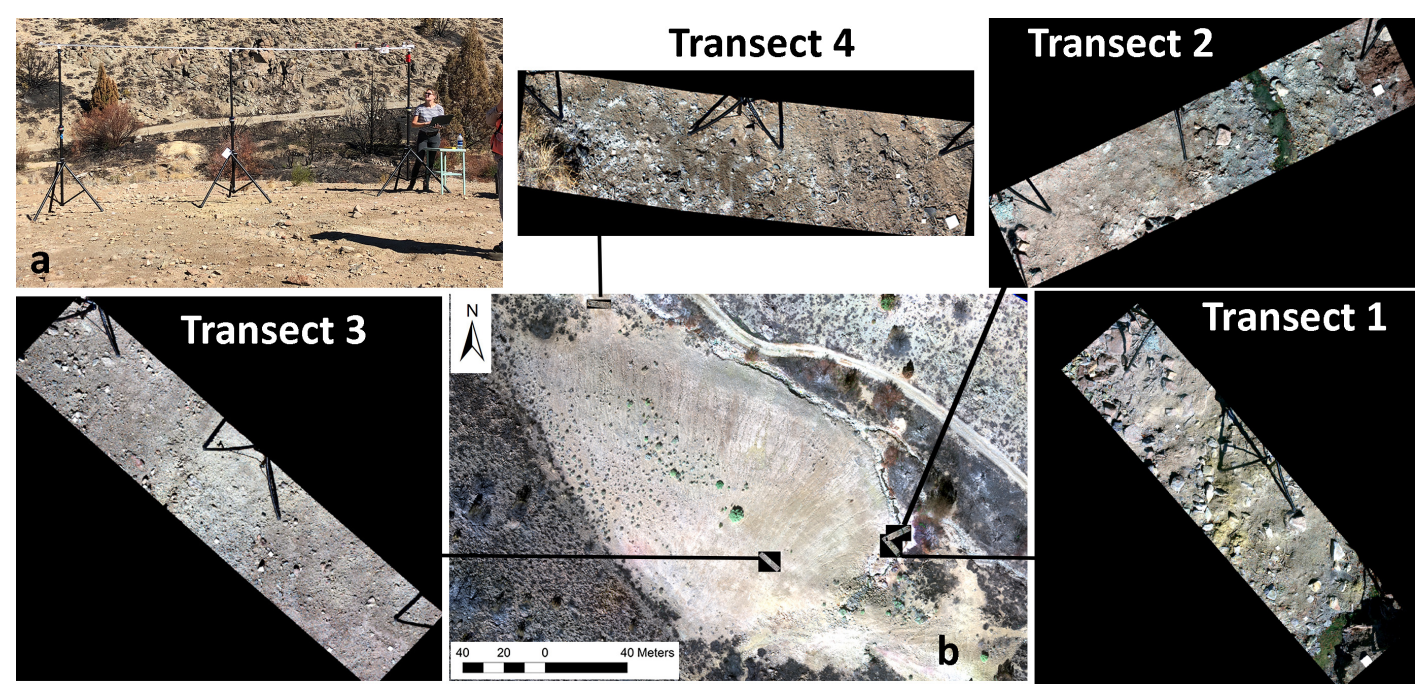

Figure 3. (a) Custom-built motion-control system used for the Hyperspectral Surveys. (b) September 2018 UAS survey displaying locations for Transects 1-4 on the Jones-Kincaid waste cover, with zoomed images of Transects 1-4 using approximate true color RGB wavelengths $(668 \mathrm{~nm}, 560 \mathrm{~nm}, 475 \mathrm{~nm})$. Each Transect is $1.3 \mathrm{~m}$ wide, $5.5 \mathrm{~m}$ long.
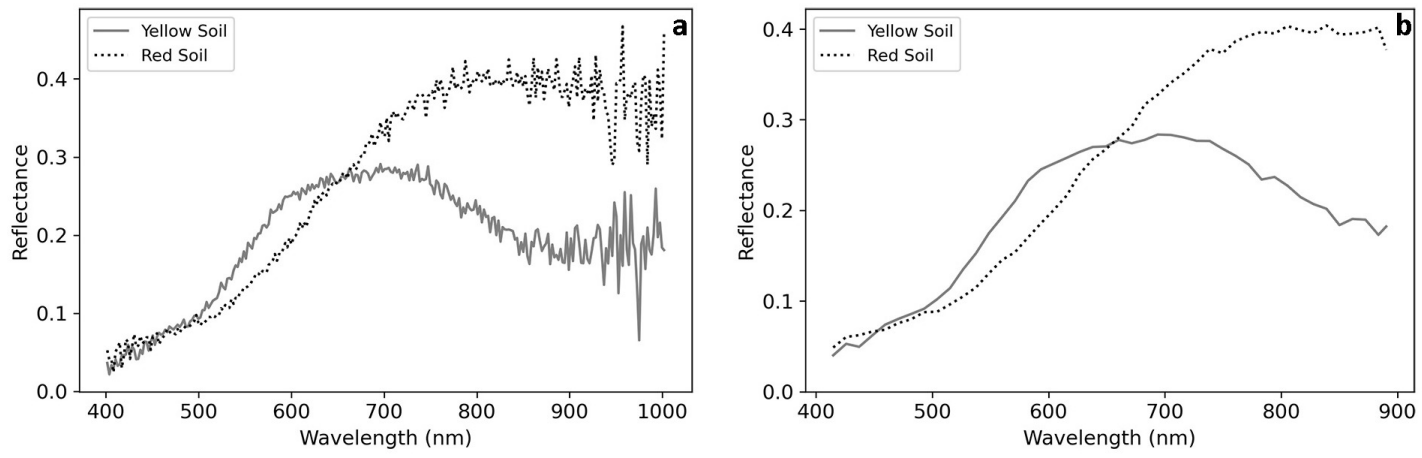

Figure 4. (a) Raw spectral profiles of yellow and red soils on Transect 2 from the 271 band Nano VNIR Hyperspec camera. (b) Spectral profiles of the same yellow and red soils on Transect 2 post spectral averaging to 45 bands.

\subsection{Mapping Methods}

We built reflectance maps with high spatial resolution and relatively low spectral resolution, to explore how accurately and by which classification algorithm PAGM or AMD can be mapped. We compared two remote sensing supervised classification methods for mapping surface materials, Maximum Likelihood (ML) [36] and Spectral Angle Mapper (SAM) [37]. We then tested a rapid, unsupervised classification algorithm (Band Math Ratios (BMRs)), that has been used to map AMD with success [15]. Both ML and SAM required determination of initial classes or training areas. Our classes of interest included AMD, jarosite, iron oxides, and EMS. We included a soil training area in order to have a control class. We based the selection of training areas on initial site characterization from 2004, and field observation data from the RPAS flights, which confirmed the presence of AMD, iron oxides (red soils), jarosite (yellow soils) and EMSs. We explored two different Band Math Ratios (BMRs) to distinguish jarosite from iron oxides. For each image we masked vegetation using a Normalized Difference Vegetation Index (NDVI) and in some instances we restricted scene analysis to just the area of the mine waste rock pile.

\subsubsection{Maximum Likelihood Classification}

We first mapped temporal changes using the Maximum Likelihood classification (ML). We classified AMD, soil, jarosite, iron oxides, and EMS on each multispectral survey. ML is 
a supervised classification method based on the Bayes Theorem [36], where a discriminant function is used to assign a pixel to the class with the highest likelihood.

$$
g_{i}(x)=1 n p\left(\omega_{i}\right)-\frac{1}{2} 1 n\left|\sum_{i}\right|-\frac{1}{2}\left(x-m_{1}\right)^{\tau} \sum_{i}^{-1}\left(x-m_{i}\right)
$$

where $i$ is the class, $x=n$-dimensional data (where $n$ is the number of bands) and $p\left(\omega_{i}\right)=$ probability that class $\omega_{i}$ occurs in the image and is assumed the same for all classes, $\left|\sum_{i}\right|$ is the determinant of the covariance matrix of the data in class $\omega_{i}, \sum_{i}^{-1}$ is its inverse matrix, and $m_{i}$ is the mean vector [36].

We defined separate training data for each individual survey using defined polygons which visually represented each class based on distinctive colors. In our case, yellow soil represented jarosite, red soil and red rocks represented iron oxides, orange colored drainage from the adit represented AMD, and white and blue soils in and around the adit and downstream of the Jones-Kincaid represented EMS. ML utilized the training data to estimate the means and variances of each class to estimate the probability and a frequency distribution for pixels with different training classes. A zone of overlap depicted the pixel values which were common to a specific class, and the pixel with the largest zone of overlap was chosen for the classification. We assigned different thresholds for each class and each survey, which are outlined in Table 4.

We attained an accuracy assessment post classification by assigning 50 random pixels to each class (predicted values), for every classified survey. We then manually inspected each random pixel and visually confirmed whether the point was correctly classified. We amended inaccurate classifications by manually assigning the correct classification to the random pixel (truth values), resulting in two datasets which consisted of predicted values and truth values. We then used this data in ENVI (version 5.5) to return confusion matrices computed from the input truth values and predicted values. The confusion matrices were used to calculate the overall accuracy $(\%)$ and the kappa coefficient. The kappa coefficient $(\kappa)$ measured the agreement between predicted values and truth values, where 1 represents perfect agreement, and 0 represents no agreement. The kappa coefficient is computed as follows:

$$
\kappa=\frac{\sum_{i=1}^{n} m_{i, i}-\sum_{i=1}^{n}\left(G_{i} C_{i}\right)}{N^{2}-\sum_{i=1}^{n}\left(G_{i} C_{i}\right)}
$$

where $i$ is the class number, $N$ is the classified values compared to truth values, $m_{i, i}$ is the number of values which belong to the truth class $i$ that have also been classified as $i, C_{i}$ is the total number of predicted values in class $i$, and $G_{i}$ is the total number of truth values in class $i$.

Table 4. Thresholds for Maximum Likelihood, where a - indicates that no threshold was used.

\begin{tabular}{ccccccc}
\hline Class & J18 & S18 & N18 & M19 & J19 & O20 \\
\hline Soil & - & - & - & - & - & - \\
Jarosite & 0.3 & 0.3 & 0.3 & - & - & - \\
Iron Oxides & 0.3 & 0.3 & 0.1 & 0.5 & - & - \\
AMD & - & - & - & 0.2 & - & - \\
EMS & - & - & - & - & - & - \\
\hline
\end{tabular}

\subsubsection{Spectral Angle Mapper}

We applied Spectral Angle Mapper (SAM) [37] to classify soil, jarosite, and iron oxides, and utilized existing endmember reference spectra derived from spectral libraries sourced from the United States Geological Survey (USGS) database [31] in ENVI (version 5.5) (Figure 5a). The USGS endmember spectrum for iron oxides was an acid mine drainage assemblage, 
which is a mixture of secondary iron mineral precipitates coating a rock surface [31]. Taking this into consideration, we combined the AMD and iron oxide (AMD $\backslash$ iron oxide) into one class for SAM and labeled the class as "iron oxide". The USGS endmember reference spectra were both higher spectral resolution and covered a longer wavelength range than either the multispectral or hyperspectral sensors. We used ENVI to resample the USGS data in to the same 45 bands (Figure 4 ) as shown in (Figure 5b) or 5 multispectral channels (Figure 5c). We provided the wavelengths and FWHM values for each band, used a Guassian model with FWHM spacings to resample the spectra of the USGS endmembers. We combined the four Jarosite species from the USGS into one jarosite class (Figure $5 b, c$ ). We removed the EMS from the SAM classification because there is no appropriate USGS reference spectrum for this particular class. Here we restricted scene analysis to just the area of the waste rock pile and part of Perry Creek.
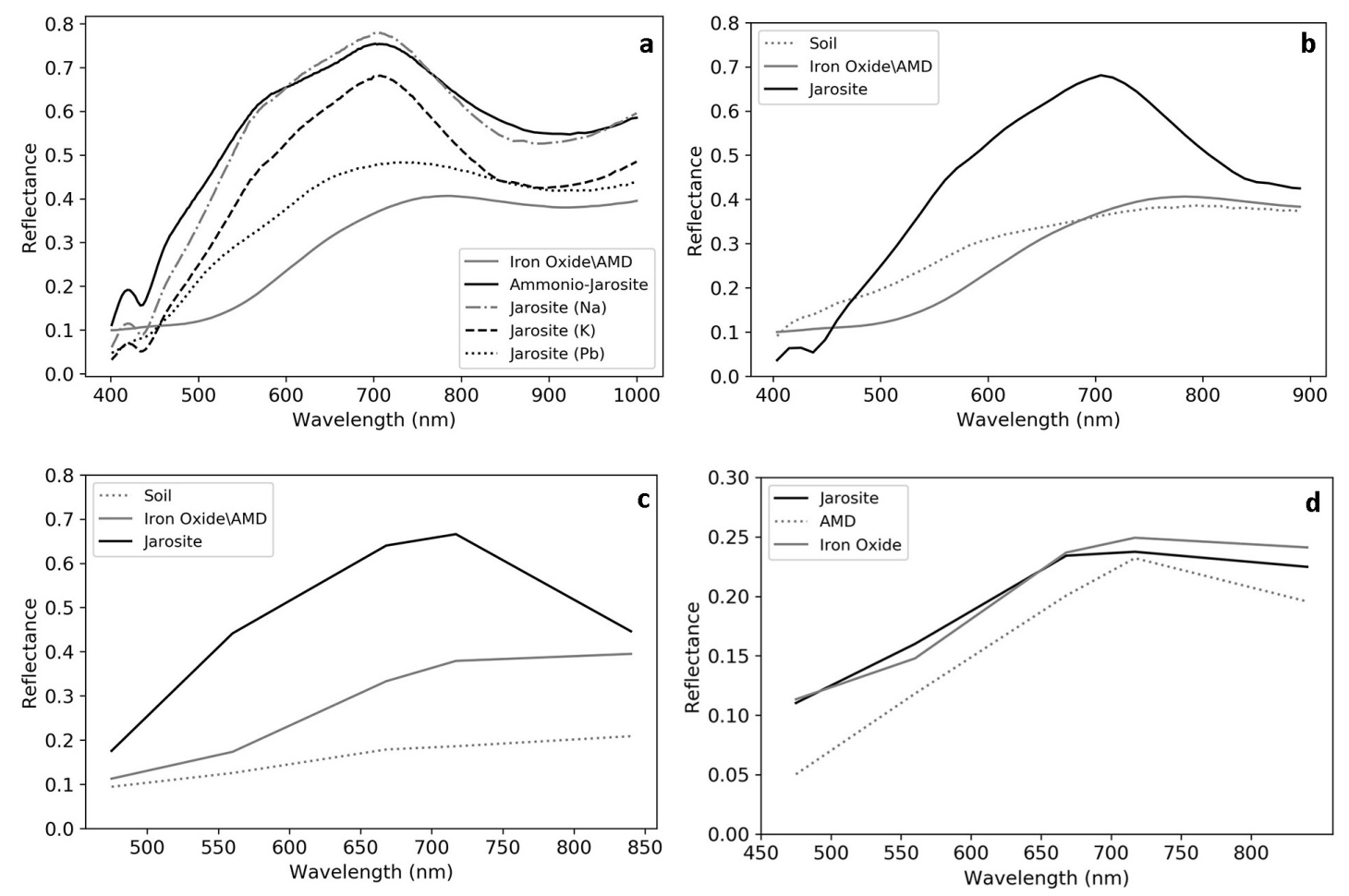

Figure 5. (a) USGS Spectral Library Database (400-1000 nm), including 4 jarosite species and the iron oxide acid mine drainage assemblage, which is a mixture of secondary iron mineral precipitates coating a rock surface. (b) USGS Database re-sampled 45 bands from 450 to $850 \mathrm{~nm}$. We combined the 4 jarosite species in to one class. (c) USGS Database re-sampled to 5 bands from 450 to $850 \mathrm{~nm}$, with the 4 jarosite species combined in to one class. (d) Spectral profiles for iron oxide, AMD, and jarosite derived from ML classification polygons. These scene-derived endmembers show less pronounced shapes than the library minerals, but exhibit similar trends to the re-sampled USGS data in (c). Iron oxide has an upturn and steep slope from 550 to $650 \mathrm{~nm}$, while jarosite has a downturn from 700 to $850 \mathrm{~nm}$. The shape of the AMD profile exhibits both trends.

SAM classification is based on a comparison of the spectral image with an endmember reference spectrum. SAM treats the reference spectrum and the image spectrum as vectors, where dimensionality is equal to the number of bands, and calculates the inner (dot) product between these vectors which results in an angle.

$$
\alpha=\arccos \frac{\Sigma X Y}{\sqrt{\Sigma(X)^{2} \Sigma(Y)^{2}}}
$$

where $\alpha$ is the angle between the reference and the image spectrum, $X$ is the image spectrum, and $Y$ is the reference spectrum. The angle $\alpha$ presents a variation anywhere between 0-90 degrees, and smaller angles represent closer matches to the reference spectrum. 
We applied the same threshold angle of 0.1 for all surveys, and as a result, any unclassified pixel had a threshold angle greater than 0.1 . The result was a classified image which shows the best match to a given reflectance material for each pixel, in each survey. We followed similar post classification steps as outlined in the previous section using a unified threshold angle of 0.1 for the SAM classification. Each random point was manually inspected using the spectral profiles to confirm whether the point was correctly classified.

\subsubsection{Band Math Ratios}

For our final mapping method, we implemented band math ratios (BMRs) to classify jarosite and iron oxides on similar scene areas used for SAM. BMRs enhanced the spectral differences between bands by dividing one spectral band by another, producing an image that provided relative band intensities. We used both the reference spectrum derived from the ML polygons and the USGS profiles to choose our band ratios (Figure $5 c, d$ ). We applied $\frac{\text { red }}{\text { green }}\left(\frac{668}{560} \mathrm{~nm}\right)$ to capture the upturn representing iron oxides, and $\frac{\text { red }}{N I R}\left(\frac{668}{840} \mathrm{~nm}\right)$ to capture the downturn representing jarosite. The sharp downturn for jarosite in the USGS profiles began at $725 \mathrm{~nm}$ (Figure 5c), whereas the weaker downturn for jarosite in the ML polygons began at $700 \mathrm{~nm}$ (Figure 5d). The ML spectra were derived using defined polygons which visually represented each class based on distinctive colors, whereas the USGS spectra were derived from pure minerals. As a result, the ML polygons did not contain pure jarosite minerals, resulting in weaker features. We applied both $\frac{\text { rededge }}{\text { NIR }}\left(\frac{725}{840}\right)$ and $\frac{\text { red }}{\text { NIR }}\left(\frac{668}{840}\right)$ to map jarosite, and we ultimately found no difference between the two ratios. The downturn of the AMD profile matched that of the jarosite downturn, and the upturn matched that of the iron oxide profiles (Figure 5c,d). AMD was only present in a small number of pixels in three surveys along the adit drain, so we used the classes which have the most pixels, jarosite and iron oxides. We masked vegetation in the images using the Normalized Difference Vegetation Index (NDVI) and threshold regions of interest (ROIs) in ENVI. We then created ROIs using two different unified thresholds for jarosite and iron oxides to represent the mapped classes. We applied a threshold of 1.05-1.1 for jarosite, and 1.7-2.3 for iron oxides on each survey.

\subsubsection{Validation: Field Data and Soil Sample Analysis}

We collected seven samples from the four hyperspectral transects previously described in Section 2.4. The samples were outsourced to AuTec Innovative Extractive Solutions Ltd., Vancouver, BC, Canada, where they were analyzed with XRD, and peaks were determined using HighScore Plus software by Panalytical with the the Crystallography Open Database (COD) [38]. Sample preparation and XRD details are listed in Appendix A (Tables A1 and A2).

Based on our study of the six RPAS flights we selected six locations for measurement using a portable field spectrometer and additional sample collection and analysis. Sample locations were selected based on the presence of AMD materials identified in the RPAS surveys. During the O20 RPAS flight we used a Spectral Evolution RS-5400 Portable Spectroradiometer (350-2500 nm), using both the 5 degree FOV lens and the sun as a source and the contact probe with internal halogen source. For interpretation of the field spectra we used standard spectral libraries available in ENVI and from the USGS [31].

Due to the persistent mapping of jarosite in one location, we dug a $0.3 \times 0.3 \mathrm{~m}$ trench in order to understand whether this was forming at the surface or continuously exposing a jarosite hot spot. We collected yellow soil samples on the surface, at 0.2 and $0.3 \mathrm{~m}$ depth. We dug a similar trench $3.6 \mathrm{~m}$ west of this location and collected brown soil samples at 0.2 and $0.27 \mathrm{~m}$ depth. We also collected blue EMS samples and red soil samples at other locations. The XRD instrument and COD database [38] was available as part of the Chemistry Shared Instrument Lab at UNR. XRD details on these samples are listed in Appendix A (Table A2). 


\section{Results}

We first discuss classification results for the RPAS surveys for each time increment and each classification method in the 29-month period of observation. We then outline our validation results from XRD on collected soil samples, the October 2018 hyperspectral rail surveys, and the 2020 field studies. We identified several locations where jarosite was mapped persistently, including Transects 1-3 (1,2,3), two zones of yellow soil (Y, site of the trench, and T2), and southeast of the adit (E). The trench site adjacent to $\mathrm{Y}$ with no yellow soil was labeled S. Iron oxides were consistently mapped at site A, and the EMS and red soil at B and E, respectively, were only mapped with the ML (as described in Section 2.4.1). The sample locations can be found on the June 18 maps in Figures 6-8, and in detail on Figures 9 and 10.

\subsection{Maximum Likelihood}

The overall accuracy for the total 29-month period using Maximum Likelihood was $72.5 \%$, with a Kappa Coefficient of 0.6502 (Figure 6). As noted in the individual surveys (Figure 6), accuracies ranged from a low of $61 \%$ to a high of $87 \%$. Jarosite hotspots were consistently mapped in Y, T2, E and Transects 1-3 $(1,2,3)$ (locations are noted on the June 18 map). Iron oxides were mapped in A and the west end of E, and EMS was consistently mapped along the adit drain and at location B in all surveys except March 19. Visual inspection of the imagery (Figure 2) confirmed this to be accurate. Jarosite was classified with over 90\% accuracy in June 2018, September 2018, November 2018, and July 2019, and over $80 \%$ in March 2019 and October 2020. Iron oxides were classified with 100\% accuracy in June 18 , but soil was misclassified as iron oxides $12 \%$ of time, resulting in an over-classification of iron oxides across the waste rock pile. Iron oxides were mapped with close to or over 90\% accuracy in November 2018, March 2019, July 2019, and October 2020. EMS was classified with $100 \%$ accuracy in September 2018, and close to or over $90 \%$ in June 2018 and November 2018. Soil was misclassified as EMS 12\% of the time in March 2019, and $23 \%$ of the time in October 2020. The overall error in accuracy for each survey were misclassifications of soil as iron oxides or EMS in June 2018, March 2019, and October 2020. AMD had fewer than 50 pixels in every survey except for March 2019 so we performed an accuracy assessment only on March 2019, where AMD was classified to 100\% accuracy as discharging out of the adit and into Perry Creek. Visual inspection of the imagery and the waste pile during RPAS deployments confirmed AMD discharge for March 2019, July 2019, and September 2018. AMD was not classified but present in July 2019 and September 2018. Confusion matrices for each classification are displayed in Appendix B (Tables A3-A8).

\subsection{Spectral Angle Mapper}

The overall accuracy for the total 29-month period using spectral angle mapper was $80 \%$, with a Kappa Coefficient of 0.7104 and ranges from $70 \%$ to $94 \%$ accuracy (Figure 7). Jarosite hotspots were again consistently mapped in $\mathrm{Y}, \mathrm{T} 2$, E and Transects $1-3(1,2,3)$, and iron oxides were consistently mapped in A (locations are noted on the June 18 map). Iron oxides $\backslash$ AMD were mapped discharging from the adit in March 19 and September 2018, but were not mapped in July 2019. Jarosite was classified with 100\% accuracy in June 2018, September 2018, November 2018, and October 2020, and over 90\% accuracy in March and July 2019. Iron oxides $\backslash$ AMD were classified with over $90 \%$ accuracy in October 20, July 2019, March 2019, and June 2018, and 100\% accuracy in September and November 2018 was classified as an iron oxide close to or over $20 \%$ of the time in June 2018, September 2018, November 2018, and October 2020, and soil was classified as jarosite less than $20 \%$ of the time in all surveys except for November 2018. Confusion matrices for each classification are displayed in Appendix C (Tables A9-A14). 


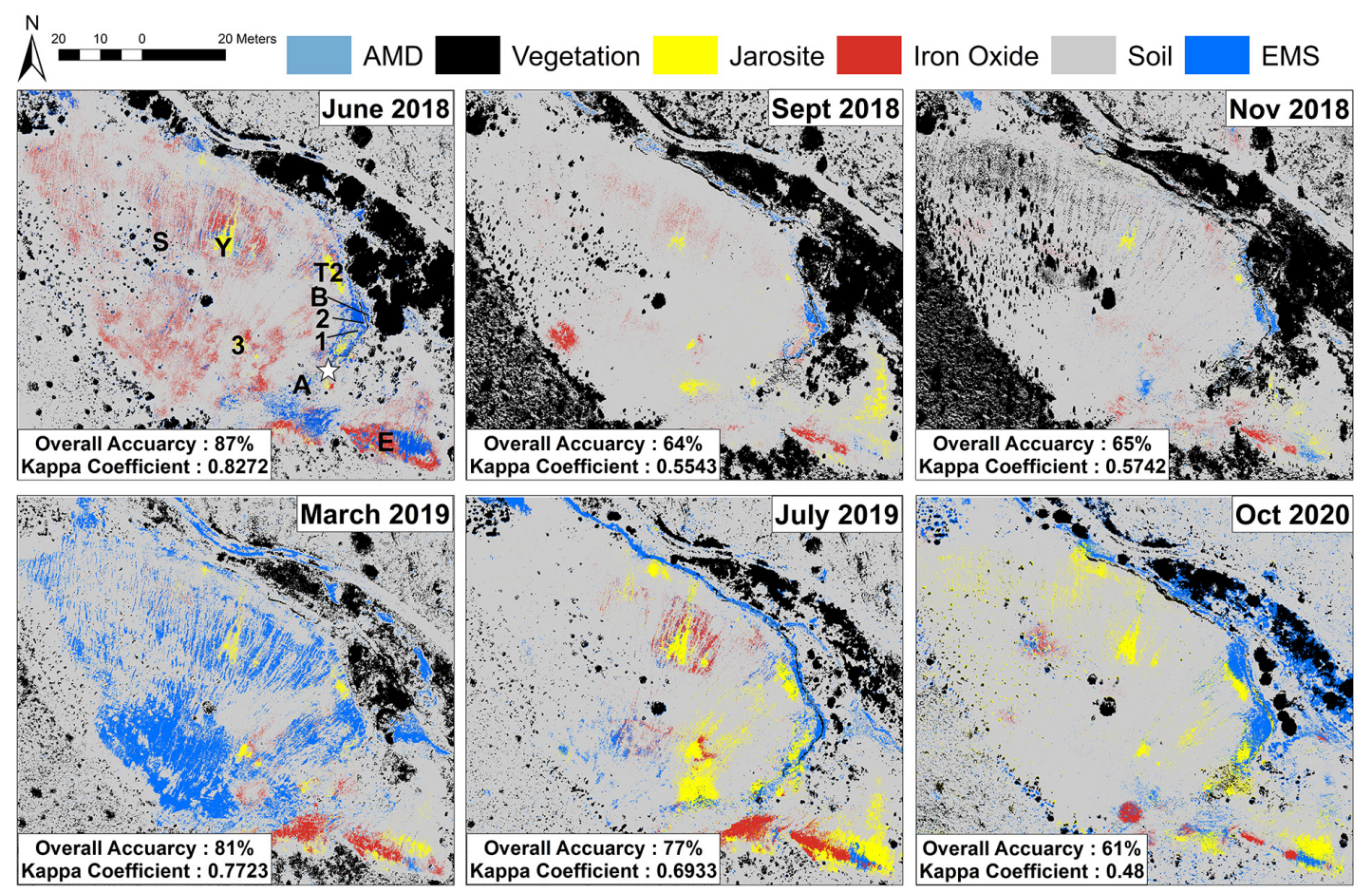

Figure 6. Results of Maximum Likelihood Classification for each remotely piloted aerial system survey. Overall Accuracy for all six surveys is $72.5 \%$, with a Kappa Coefficient of 0.6502. Locations for ground surveys are indicated on the June 2018 map for Y, T2, B, A, E, S, and Transects 1-3 (1,2,3), and the adit drain is indicated with a star. Each scene is $240 \mathrm{~m}$ wide and $184 \mathrm{~m}$ tall.

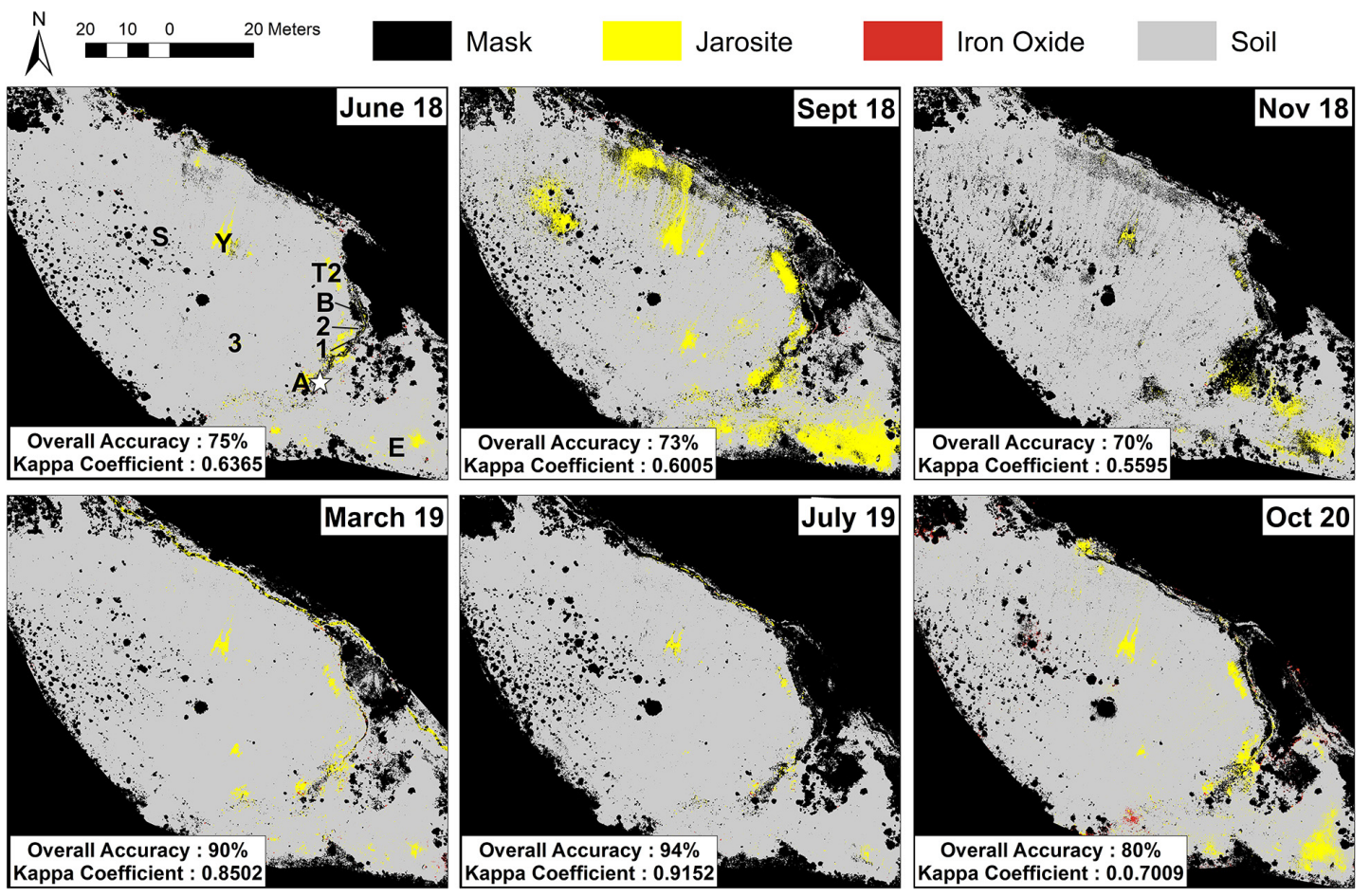

Figure 7. Results of Spectral Angle Mapper Classification for each remotely piloted aerial system survey. Overall Accuracy for all six surveys is $80 \%$, with a Kappa Coefficient of 0.7104 . Locations for ground surveys are indicated on the June 2018 map for Y, T2, B, A, E, S, and Transects 1-3 (1,2,3), and the adit drain is indicated with a star. Each scene is $134 \mathrm{~m}$ wide and $118 \mathrm{~m}$ tall. 


\subsection{Band Math Ratios}

Because band math ratios is a thresholded value, rather than a pixel classification, we could not perform an accuracy assessment similar to ML or SAM. However, we visually saw the same jarosite and iron oxide patterns from the previous classification methods at $Y$, T2, E, A, and Transects 1-3 (1,2,3) (Figure 8). BMRs did not map iron oxides on the west end of $E$ in any survey, and AMD was mapped as jarosite in September 2018, March 2019, and July 2019.

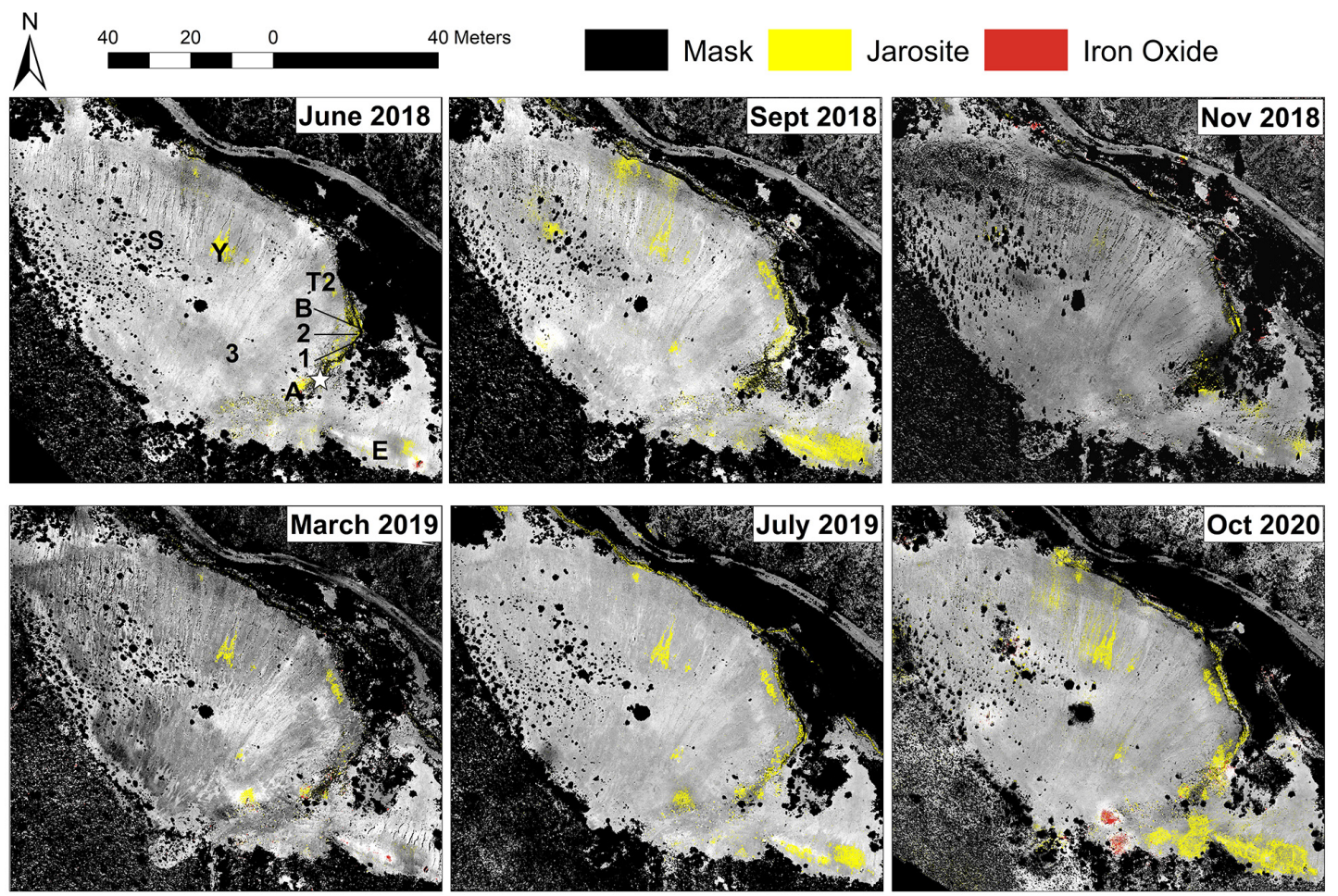

Figure 8. Results of Band Math Ratios for each remotely piloted aerial system survey. Locations for ground surveys are indicated on the June 2018 map for Y, T2, B, A, E, S, and Transects 1-3 (1,2,3), and the adit drain is indicated with a star. Each scene is $134 \mathrm{~m}$ wide and $118 \mathrm{~m}$ tall.

\subsection{Validation: X-ray Diffraction Soil Analysis}

Soil samples were collected on the Jones-Kincaid mine waste pile in October 2018 and again in October 2020. XRD analysis on the October 18 soil samples detected varying modal abundances of jarosite at 58, 19.1, and $14.6 \mathrm{wt} \%$ at Transects $1-3$, respectively, and a minor abundance of pyrite at $0.6 \mathrm{wt} \%$ at Transect 2 (Table A1). Trace phase grouping definitions, mineral identification results, and the ideal chemical formulas are listed in Appendix A (Table A1). The XRD ground surveys in October 20 were used to confirm the presence of jarosite and iron oxides in areas where they were mapped. Although various mineral assemblages exist within these soil samples, we focused solely on the presence of jarosite and iron oxides. Jarosite was detected in the red soil at $\mathrm{E}$, and at $\mathrm{Y}$ on the surface, and at $0.2 \mathrm{~m}$ and $0.3 \mathrm{~m}$. We did not detect any jarosite peaks in S, and hematite, an iron oxide, was detected in the red soil at E. XRD patterns for all October 20 samples had three strong peaks which were indicative of quartz. XRD profiles and $2 \theta$ peak values for all soil samples are shown in Appendix D (Figure A1). Unfortunately, pentahydrate was not in the COD database, and therefore we relied on the spectral profiles taken in the field for identification.

\subsection{Validation: Hyperspectral Transects}

We performed validation of the September 2018 RPAS survey using the SAM classification on the hyperspectral data from Transects $1-3$. We chose Transects 1-3 because they had 
confirmed modal abundances of jarosite (Table A1), and we validated the September 2018 RPAS survey because it was the closest survey in time to the October 2018 hyperspectral data collection. We represented the validation using the September 2018 BMR image, although each classification analysis mapped jarosite in these three transects, not only in September 2018, but in every other multispectral survey (Figure 9). By representing this one RPAS survey we then confirmed the locations in all surveys.
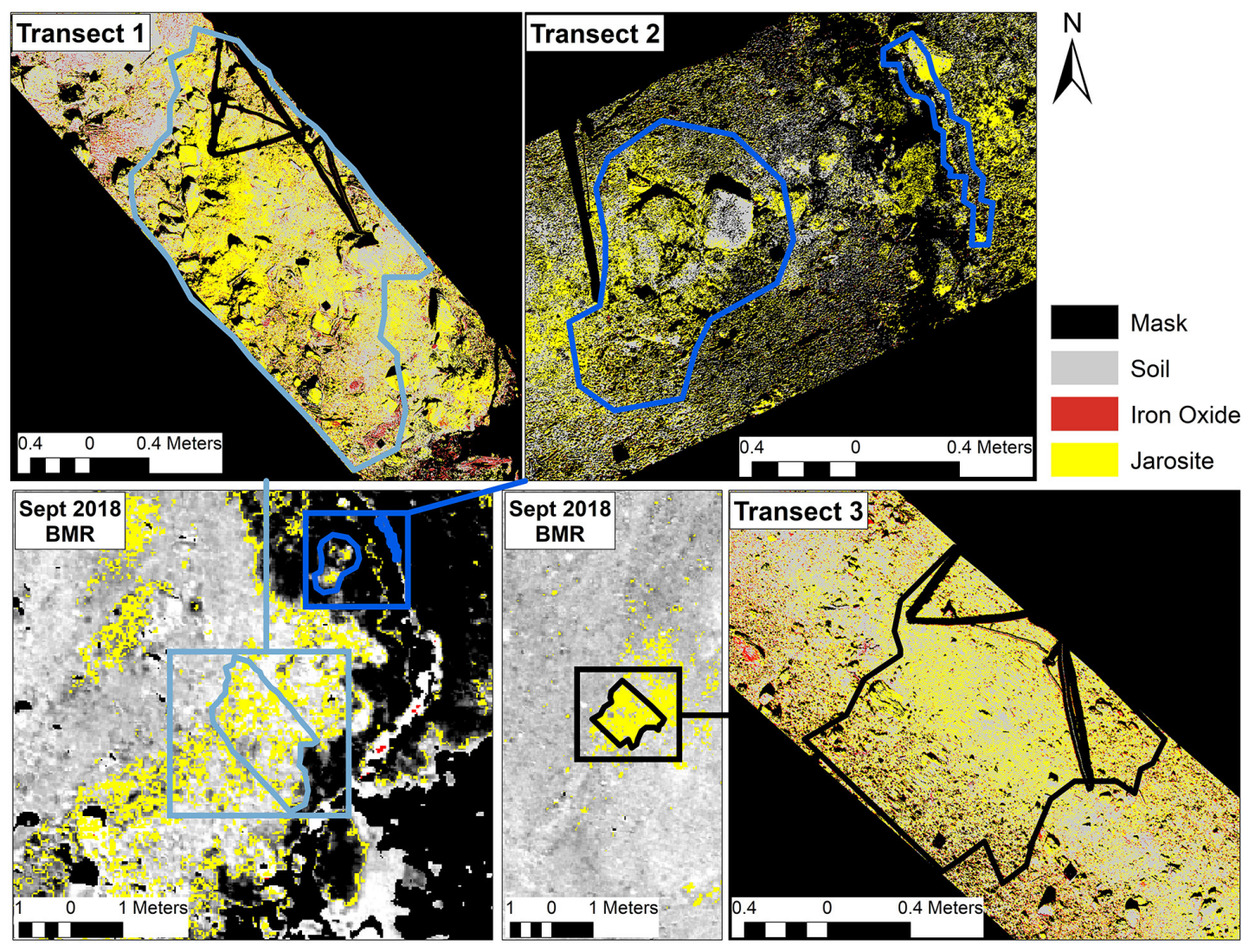

Figure 9. Validation of jarosite in the September 2018 Band Math Ratio classification in Transects 1-3. Jarosite is outlined in black on Transect 3, in dark blue on Transect 2, and in light blue on Transect 1. Each transect location and mapped jarosite area is highlighted on the corresponding September 2018 band math ratio map as called out by color bars linking the band math ratio image to the hyperspectral data.

\subsection{Validation: Field Portable Spectroradiometer}

Additional validation included a field portable remote sensing spectroradiometer at locations Y, T2, B, A, and E (Figure 10). These data exhibited the jarosite absorption feature at $450 \mathrm{~nm}$ in all areas with yellow soil (Y, T2, and E) (Figure 11). The spectral profiles for the three samples taken at A showed an upturn and steep slope from 500 to $700 \mathrm{~nm}$, indicative of an iron oxide (Figure 11). The red soil at E displayed an absorption feature at $450 \mathrm{~nm}$ and a bumpy slope from 550 to $700 \mathrm{~nm}$ (Figure 11), which is similar to the USGS spectra of an iron oxide paint pigment [31]. The blue EMS at B had a wide absorption feature at approximately $800 \mathrm{~nm}$ (Figure 11), indicative of the copper sulfate salt pentahydrate [39]. Pentahydrate is a common bright blue copper sulfate salt [40] which forms as an EMS from waters containing iron and sulfate, the products of pyrite oxidation [2]. 


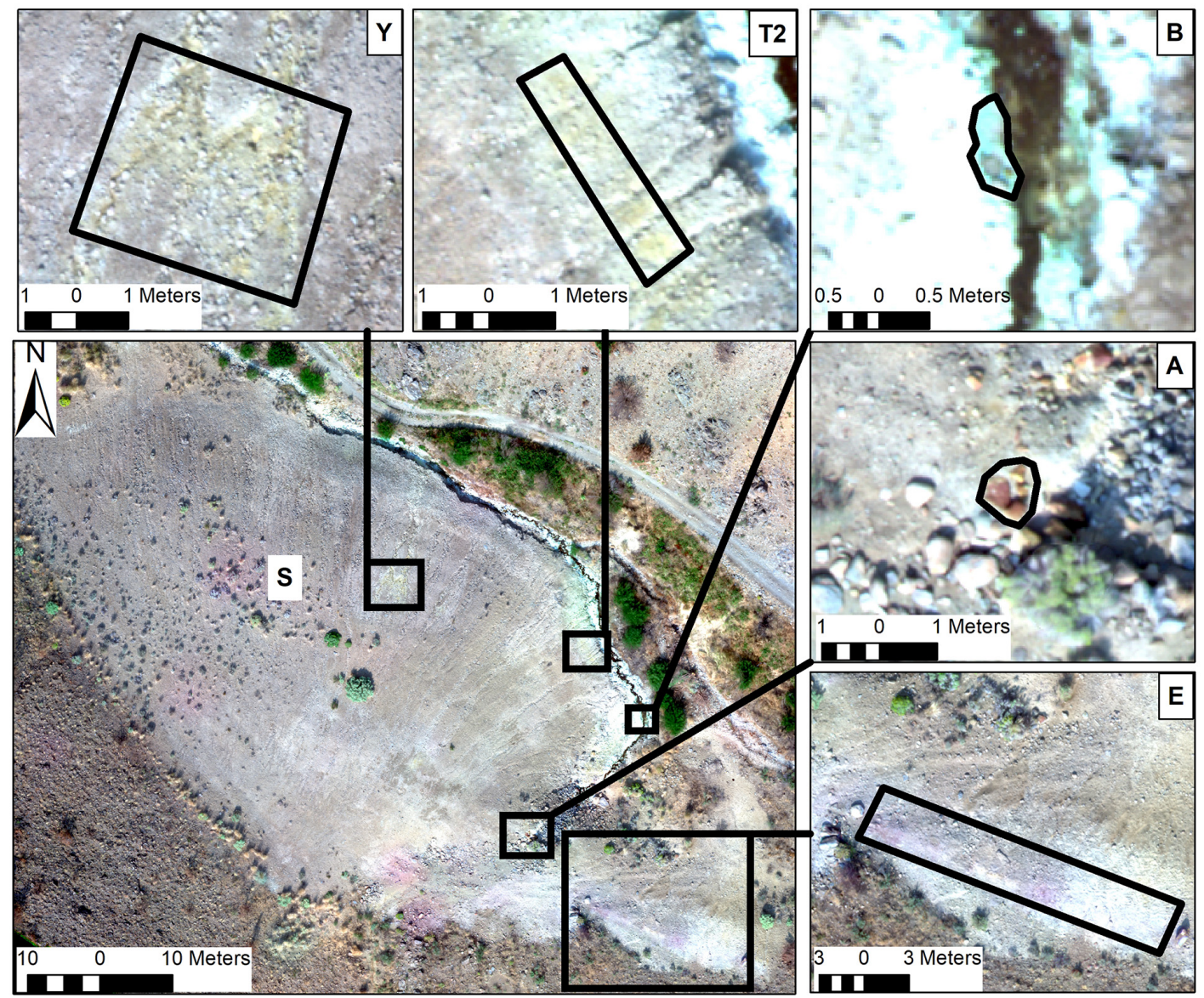

Figure 10. Locations for the field spectral measurements in October 2020. Y, T2, B, A, E, locations are represented by boxes on the October 2020 reflectance map, and the zoomed in images indicate the exact locations for spectra shown in Figure 11. $\mathrm{S}$ is the location of the second trench site.
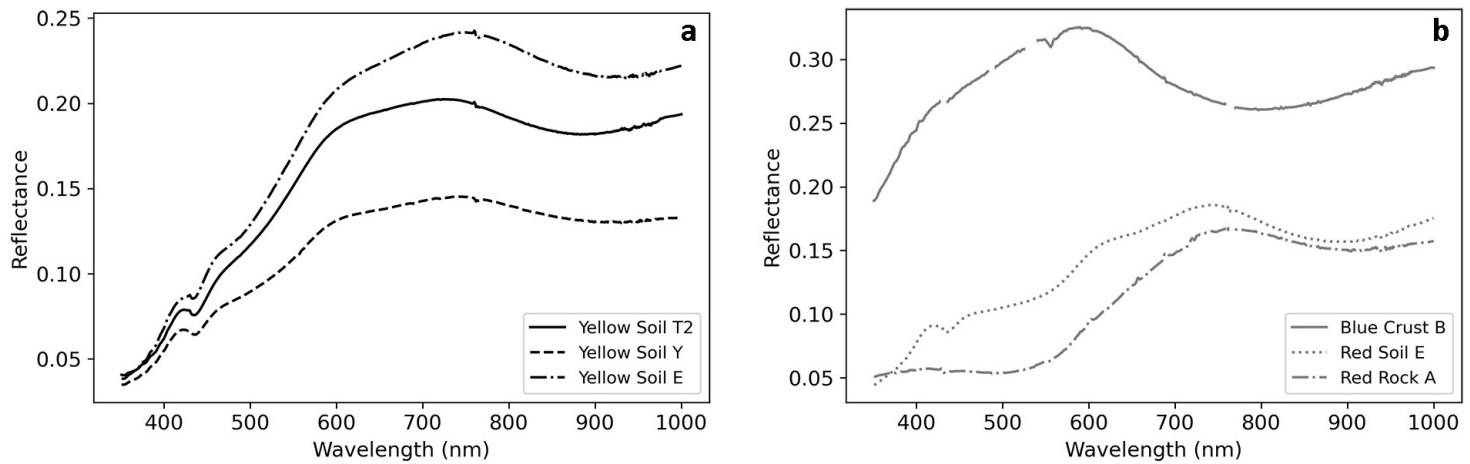

Figure 11. Spectral profile results of the October 2020 ground survey. (a) Yellow soil spectral profiles at Y, T2, and E. (b) Spectral profiles for EMS at B, and red soils at E and A. Each field spectroscopy sample was taken with the field portable remote sensing spectroradiometer. See Figure 10 for locations.

\section{Discussion}

Our goal was to monitor PAGM and AMD at the Perry Canyon, NV AML using an RPAS equipped with a 5-band multispectral sensor. We investigated two supervised classification methods, maximum likelihood (ML) and spectral angle mapper (SAM), and one unsupervised method, band math ratios (BMRs). We tested how accurately and efficiently each method could be used to classify and map PAGM and AMD. To our knowledge, these techniques have not been used in conjunction with high spatial resolution 
and low spectral sampling reflectance maps to monitor AMLs. We then used various validation methods to test the accuracy of the established supervised and unsupervised classification algorithms. We created multi-temporal maps of PAGM and AMD, and make recommendations for future use of these techniques on AMLs. These methods are not a replacement for ground measurements; however, we showed that a RPAS combined with broadband multi-channel sensors have the potential to monitor high priority AMLs and guide in silico work.

\subsection{Comparison of Accuracy of Classification Algorithms and Costs Versus Benefits of Each}

\subsubsection{Maximum Likelihood}

We tested three different classification methods, with the first being Maximum Likelihood (ML). Although ML is a commonly used classification scheme, for this study we found implementation across multiple surveys to be time consuming with a high degree of inaccuracy. We were unable to use the same training data for each flight such that training areas had to be independently selected for each survey. We also had to use different thresholds for each class because ML classifies every pixel in the image, so thresholds were set to minimize classification inaccuracies. For example, ML over-classified iron oxides in June 18 , even with a threshold of 0.3 , and only classified them to greater than $70 \%$ accuracy in September and November 2018 because the threshold was 0.3. The advantage of ML is that we were able to map AMD and efflorescent mineral salts (EMS) as their own classes. However, ML only classified AMD in March 19, and did not classify it in September 2018 and July 2019, although it was present. This is an indication that it may be difficult to map AMD dispersion from small adit seeps as its own class, even when using $\mathrm{cm}$-scale reflectance maps. EMS was over-classified in July 2019, March 2020 and October 2020 without using a threshold (Figure 6). In general, EMS are white in the reflectance images due to the salt content (Figure 2). However, flying in very sunny conditions, as was the case with most of our surveys, also produces high albedo areas in the data. These high albedo areas are evident in the true color images of each survey (Figure 2) and could be a reason EMS was consistently misclassified. This is an indication that it may be difficult to distinguish between efflorescent mineral salts and high albedo areas when using a broadband sensor in conjunction with the ML pixel classification. It is unlikely that applying a threshold to this class would have mitigated this issue. For the ML classification, we did not mask all surfaces outside of the Jones-Kincaid waste rock pile and Perry Creek. Although this may have helped increase our accuracy, we do not recommend maximum likelihood due to the time commitment and complicated implementation of this method across multiple surveys.

\subsubsection{Spectral Angle Mapper}

The second supervised classification method we tested was spectral angle mapper (SAM), which performed better and was easier to implement relative to ML. Utliizing the USGS database for SAM was quite simple for common acid generating materials such as iron oxides and jarosite, and a unified threshold (0.1) made the workflow seamless. The use of different thresholds might have provided more accurate maps, but at the loss of consistency across time. The major disadvantage to this method was that we could not map AMD as its own class, nor did we attempt to map EMS. With regard to EMS, there was not an appropriate mineral reference in the USGS database. With regard to AMD, there were not large regions of this material, although combining the AMD and iron oxide classes still captured the regions with potential acid generating materials (PAGM). This is evident in March 2019 and September 2018, where Iron oxides $\backslash$ AMD was accurately mapped discharging from the adit. Considering that AMD was not classified in September 2018 using ML, the best practice may be to combine AMD with iron oxides when using a broadband sensor. SAM under-predicted jarosite hotspots in November 18, and overpredicted jarosite in September 2018 (Figures 7 and 8). The over-prediction could have been caused by higher reflectance values in the September 18 image, and in this case, a lower threshold may have fixed the misclassification. The shadows in the November 
2018 image (Figure 2) and soil moisture caused by typical November rainstorms in the region, likely caused the reflectance to be lower. As clouds and soil moisture will cause a reduction in reflectance, this lead to attenuation in the SAM accuracy for November 18. We recommend that all flights take place prior to any storm events, during cloud-free conditions. SAM under-predicted iron oxides on the west side of the E location in all surveys, and instead consistently mapped patches of jarosite. We confirmed hematite in the soil at the west end of E using both field spectroscopy and XRD (Figures 11b and A1). However, the spectral profile for the red soil at E (Figure 11b) had an absorption feature at $450 \mathrm{~nm}$, and a downturn at $700 \mathrm{~nm}$, similar to the jarosite profiles (Figure 11a). Because we used a 5-band multispectral sensor, SAM mapped these areas as only jarosite. Our results suggest that the soil at E was a mixture of both jarosite and hematite, and that a broadband sensor combined with SAM will only map one class, even when two are present.

\subsubsection{Band Math Ratios}

The only unsupervised classification we tested was band math ratios (BMRs), which we found performed as well or better than SAM and ML without the added complication of assessing individual pixels or additional classes. We determined uniform thresholds by creating polygons that best fit our visual inspection of the imagery, and we masked vegetation in the images using NDVI. Although BMR did not allow for an accuracy assessment, as it depends on relative band intensities, it is the easiest to implement, and no soil control class was needed. We simplified band ratio determination by utilizing the reference spectrum from both the USGS profiles and the ML polygon profiles. Similar to SAM, we were unable to map AMD as its own class, and we did not attempt to map EMSs. AMD was incorporated into the jarosite and iron oxide endmembers, and was successfully mapped as jarosite in September 2018, March 2019, and July 2019 (Figure 8). As this was the only method which mapped AMD where it was present, we suggest that, when using band math ratios, incorporating AMD into another endmember may be the best approach to map AMD in small adit seeps. This method under-predicted iron oxides at E, again suggesting that broadband sensors, in conjunction with spectral endmember classification schemes, may only map one class even when two are present. The shadows and possible soil moisture in the N18 image also proved to be an issue when classifying jarosite using $\mathrm{BMR}$, yet the higher reflectance in the S18 image did not appear to effect the classification. This is another reason we believe that the BMR method is the simplest and best approach for mapping PAGM with a broadband sensor, as it is not as sensitive to images with higher reflectance values.

\subsection{Validation Using Hyperspectral Sensors, Ground Surveys, and Soil Analysis}

The hyperspectral surveys evaluated using spectral angle mapper, combined with XRD on selected soils, provided a robust ground-truthing method. Hyperspectral sensors have more bands with narrower bandwidths, enabling them to better detect AMD and PAGM than the broadband 5-channel MicaSense sensor. In the hyperspectral data, the absorption feature of jarosite at $450 \mathrm{~nm}$ was clearly identified in the spectral profiles (Figure 4), allowing confident mapping of the distribution of this material (Figure 9). Future use of a RPAS equipped with a hyperspectral sensor could be used to survey the entire field area. The algorithms would most likely not require absorbing AMD into other endmembers, as was necessary with the broadband sensor. In addition, classifying EMS with the appropriate field collected spectra, would most likely be possible. This method of mapping AML is a promising area of future work once this type of sensor is more readily available to fly large areas on a RPAS.

We performed an extra validation step using a handheld spectrometer in areas along the Jones-Kincaid mine waste rock pile. Ground-truthing using the handheld spectrometer clearly identified the spectral signatures of jarosite and iron oxides at locations where they were mapped using the broadband multispectral sensor (Figure 10). Although we were unable to map EMS using spectral angle mapper and band math ratios, and it proved 
difficult to map them accurately with maximum likelihood, their presence indicates that EMS enriched with heavy metals were continuing to actively discharge into Perry Creek. The continued presence of EMS may indicate that further remediation may need to be implemented, and that an analysis of heavy metals in the soil and in the EMS may need to be investigated to gain further insight into the contamination of Perry Creek. Future studies may be able to map EMS using field collected spectra as an endmember for SAM. However, we did not test the field spectra we collected in our study.

\subsection{Interpretation of Multi-Temporal Maps of PAGM and AMD}

The persistently mapped 'hotspots' of jarosite on the Jones-Kincaid mine waste cover are an indication that jarosite is either forming on the surface, or is being exposed due to cover erosion over time. We mapped the same jarosite 'hotsposts' throughout each RPAS survey and with each classification technique. Jarosite was consistently mapped at $\mathrm{Y}, \mathrm{T} 2, \mathrm{E}$, and Transects 1-3. We confirmed jarosite at $Y$ and Transects 1-3 using soil samples and XRD from the October 18 and October 20 ground surveys (Table A1 and Figure A1), and using field spectroscopy at $\mathrm{Y}, \mathrm{T} 2$, and $\mathrm{E}$ (Figures 10 and 11a). The waste rock cover has been eroding over time during large storm events, suggesting that jarosite was being exposed as a result of erosion at $Y, T 2$, and $E$, and not necessarily forming on the surface. The XRD results from the trench at $Y$ confirmed this, as jarosite was present from the surface to at least a depth of $0.3 \mathrm{~m}$. Jarosite was not detected at the adjacent trench site $\mathrm{S}$, which implied that jarosite does not exist everywhere on the waste pile, but only in certain areas. This was consistent with our classification maps, as jarosite was not mapped everywhere on the waste rock. Based on the high levels of sulfates in the 2004 site characterization report and our validation data, we believe that jarosite was most likely already present on the mine waste pile prior to cover installation, and is being exposed via erosion in $\mathrm{Y}, \mathrm{T} 2$, and $\mathrm{E}$. However, the XRD results from the O18 ground surveys show that jarosite was present on the surface of Transects 1-3. Jarosite may have been forming on the surface due to adit seepage at Transects $1-2$, and groundwater seepage at Transect 3 . The pyrite at T2, although a small amount, was indicative of the potential for active AMD formation, which can lead to the formation of secondary sulfates such as jarosite. The pipe installation during remediation was laid in order to redirect mine waters away from waste dump material. The waste rock did not appear to be eroding at Transect 3 based on previous change detection studies, and the presence of jarosite in this transect could be a result of various scenarios. Jarosite at Transect 3 could mean that groundwater with mobilized sulfates is seeping into the waste rock and oxidizing on the surface, or that the pipe installed during remediation is not efficiently redirecting mine waters away from waste dump material, which can also cause the formation of jarosite on the surface. In either case, jarosite was consistently mapped in all surveys in Transect 3.

Iron oxides were more difficult to accurately map using the three methods. We did, however, map iron oxides at $A$ in each survey, with each method. The iron oxide rocks at A were stable throughout each survey, and had a distinct upturned slope (Figure 11b). This is an indication that iron oxide rocks can be mapped accurately using a 5-band multispectral sensor in conjunction with both supervised and unsupervised classification schemes. The iron rich soils at $\mathrm{E}$ are most likely a mixture of jarosite and hematite, and it is likely that these are also consistent 'hotspots'. The iron rich soils were only mapped as distinct classes us the ML pixel based classification, and were mapped as jarosite using SAM and BMRs. We believe that classifying these mixed soils as jarosite sill reveals areas of PAGM on the waste rock. Therefore, we maintain that the BMR method is still the most efficent at mapping PAGM across AML mine waste piles, even in the case of mixed soils.

\subsection{Recommendations for Use on Other Abandoned Mine Lands}

Planning RPAS missions based on weather conditions and necessary time increments, is an important step for mapping temporal changes across multiple surveys efficiently. The cloud cover and possible soil moisture in the N18 survey lead to an under-prediction 
of jarosite across all methods. Multispectral sensors capture data using the light energy reflected off of objects in the environment. We recommend that flights take place within two and a half hours of local solar noon to reduce deep shadows, which can significantly affect results. The only exception would be flying in very sunny conditions with the sun directly overhead. This can produce high albedo areas which, in our case, likely caused the misclassification of EMS. The 3 to 6 months cadence of RPAS flights may not be necessary, as 'hotspots' of PAGM did not rapidly change throughout the 29-month period of our surveys. However, we did map an increase in PAGM at Y, T2, E, and Transects 1-3 $(1,2,3)$ from June 2018 to July 2019, and again from July 2019 to October 2020, indicating that yearly time-steps would be sufficient to map any changes. As erosion in arid climates generally occurs just after a large rainstorm event, it may be the best practice to plan surveys post heavy rainfall events, when the soil has dried.

Accuracy assessments for classified maps can provide an estimation as to how well a chosen method worked. However, the accuracy assessment for ML and SAM was only performed using 50 random pixels, representing less than $0.1 \%$ of the total pixels classified. While the randomized approach should be statistically representative of the scene overall, a more comprehensive assessment would need to include many more pixels for each survey that would have to be manually evaluated. This would have been extremely time consuming and made for a difficult workflow. Here we chose not to evaluate every pixel, as the goal was to make a smooth and simple workflow which can be applied to broadband sensors. Therefore, band math ratios is the most straightforward method to eliminate the labourintensive accuracy assessment, without compromising the validity of the classification.

The Jones-Kinaid mine waste pile in Perry Canyon, NV was a unique AML to fly a broadband sensor and test different supervised and unsupervised classification methods. Based on the site characterization data, we knew we were looking for sulfates and iron rich minerals associated with AMD. The yellow and red soils provided us two minerals (jarosite and iron oxides) associated with PAGM, that we could map and classify using a broadband sensor and various techniques. However, there are many other sulfates associated with PAGM and AMD, and not all of them are yellow or red in color. The advantage of using a broadband multispectral sensor is that many iron bearing sulfate minerals commonly associated with PAGM, exhibit the same spectral features within the $400-850 \mathrm{~nm}$ range. In this paper, we showed that jarosite and iron oxides can be mapped accurately with RPAS surveys using a multispectral sensor combined with the band math ratio classification. The specific band ratios we used also have the potential to map and monitor AMLs in which no previous site characterization data is available. In this regard, we found band math ratios to be the easiest and most efficient temporal mapping method for PAGM on AMLs when using a remotely piloted aerial system equipped with a 5-band multispectral sensor.

\section{Conclusions}

Temporal monitoring of PAGM and AMD in Perry Canyon using a 5-band multispectral sensor provided an alternative approach to field measurements. In particular, for small area AMLs, a RPAS with a 5-band multispectral sensor provided an efficient way to map the temporal changes of AMD and PAGM, while increasing the spatial coverage and temporal resolution over traditional field methods. When using this type of broadband sensor, we recommend that anything in the image other than the area of interest be masked using NDVI, in order to improve classification accuracy. We mapped PAGM on the JonesKincaid mine waste rock pile, including jarosite and iron oxides $\backslash$ AMD. These were readily characterized with the multispectral sensor using maximum likelihood (ML), spectral angle mapper (SAM), and band math ratios (BMRs), with consistent results between the three methods. The EMS material was not accurately mapped due to confusion with other high albedo materials, or the lack of appropriate spectral reference data. However, the persistence of EMS on the waste rock does indicate that further remediation and an analysis of heavy metals may need to be investigated to gain further insight into the contamination of Perry Creek. BMRs combined iron oxides, AMD, and jarosite, but collectively these 
classes mapped the distribution of PAGM at this site. Although each classification was efficient and accurate in different ways, for future monitoring with frequent surveys, BMR was the simplest and easiest method to map areas of PAGM using a 5-band multispectral sensor. Our multi-temporal survey classifications indicated change in PAGM exposure is occuring slowly, such that 3-6 month time-steps may not be necessary when mapping temporal changes for this particular site. Although these methods are not a replacement for ground measurements, they can be used to guide in-situ work to highest priority regions for detailed investigation and remediation. RPASs have demonstrated potential as a means to map high priority AMLs, using even broadband, multi-channel sensors like the MicaSense. Future development, such as incorporating hyperspectral sensors, is expected to improve accurate identification and mapping of many different types of PAGM.

Author Contributions: A.S.C.: methodology, validation, formal analysis, investigation, writing—original draft preparation, and visualization; W.M.C.: conceptualization, methodology, validation, investigation, writing-review and editing, and resources; S.W.M.: conceptualization, project administrator, resources, writing-review and editing, supervision, and funding acquisition; R.J.B.: conceptualization, project administrator, writing - review and editing, investigation, and funding acquisition; M.H.: investigation, validation, writing — review and editing; C.K.: investigation, validation, writingreview and editing. All authors have read and agreed to the published version of the manuscript.

Funding: This research was funded by Bureau of Land Management grant number L15AC00138.

Data Availability Statement: The data presented in this study are openly available in https:/ /www. hydroshare.org/resource/730be8a9e2b34d8dbaa70680c50e8831/ (accessed on 1 January 2021).

Acknowledgments: RPAS surveys conducted by the Center for Transformative Environmental Monitoring Programs (CTEMPs) funded from the National Science Foundation grant EAR-1429768 (Christopher Sladek, Scott Tyler, Christopher Kratt, and Marja Haagsma), Nicole Cutler with the Bureau of Land Management, Nevada, Carson City District for her collaboration and assistance on the project, and the National Science Foundation (CHE-1429768) for the purchase of the powder $X$-ray diffractometer are gratefully acknowledged.

Conflicts of Interest: The authors declare no conflict of interest. The funders had no role in the design of the study; in the collection, analyses, or interpretation of data; in the writing of the manuscript, or in the decision to publish the results.

\author{
Abbreviations \\ The following abbreviations are used in this manuscript: \\ MDPI Multidisciplinary Digital Publishing Institute \\ DOAJ Directory of open access journals \\ TLA Three letter acronym \\ LD linear dichroism \\ AMD Acid Mine Drainage \\ AML Abandoned Mine Land \\ AMLs Abandoned Mine Lands \\ BMRs Band Math Ratios \\ BLM Bureau of Land Management \\ COD Crystallography Open Database \\ ENVI Environment for Visualizing Images \\ EMS Efflorescent Mineral Salt \\ FWHM Full Width Half Maximum \\ GCPs Ground Control Points \\ GSD Ground Sampling Distance \\ AGL Above Ground Level
}




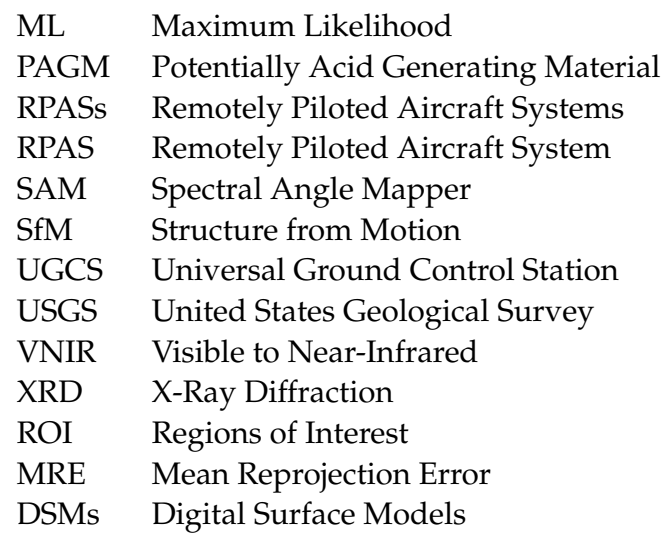

\section{Appendix A. October 2018 XRD Results}

Table A1. XRD Results for the October 2018 ground survey, including mineral identification, chemical formulas, and modal percent weight. Trace phase grouping definitions were based on weight percentage ranges, where greater than 30 were considered major phases, less than 30 and greater than 10 were considered moderate, less than 10 and greater than 2 were considered minor, and less than 2 were considered trace phases. When peak to background ratios were low, the detection limit was $2 \mathrm{wt} \%$, and when peak to background ratio was high, the detection limit could be as low as $0.5 \mathrm{wt} \%$. Each sample was ground for five minutes in a McCrone Micronizing Mill using reagent alcohol to reduce particles to between 5 and $10 \mu \mathrm{m}$.

\begin{tabular}{|c|c|c|c|c|c|c|c|c|}
\hline Mineral & Chemical Formula & T4-S2 & T4-S1 & T3-S1 & T3-S2 & T1-S1 & T2-S1 & T2-S2 \\
\hline Quartz & $\mathrm{SiO}_{2}$ & 25.2 & 23.3 & 35.6 & 33.9 & 13.1 & 27.0 & 27.0 \\
\hline Coesite & $\mathrm{SiO}_{2}$ & 0.0 & 0.0 & 0.0 & 0.0 & 6.7 & 3.9 & 0.0 \\
\hline Actinolite & $\left(\mathrm{Ca}_{2}\right)(\mathrm{Mg}, \mathrm{Fe})_{5}\left(\mathrm{Si}_{8} \mathrm{O}_{22}\right)(\mathrm{OH})_{2}$ & 3.4 & 5.0 & 4.1 & 3.2 & 0.0 & 0.0 & 0.0 \\
\hline Albite & $\mathrm{NaAlSi}_{3} \mathrm{O}_{8}$ & 22.1 & 18.6 & 18.9 & 12.3 & 0.0 & 8.3 & 12.4 \\
\hline Gypsum & $\mathrm{CaSO}_{4} \cdot 2 \mathrm{H}_{2} \mathrm{O}$ & 2.7 & 3.6 & 1.5 & 1.7 & 3.9 & 5.1 & 3.5 \\
\hline Micas & $\mathrm{KAl}_{2}\left(\mathrm{AlSi}_{3} \mathrm{O}_{10}\right)(\mathrm{OH})_{2}$ & 22.4 & 17.5 & 11.7 & 14.9 & 0.0 & 13.0 & 20.3 \\
\hline Orthoclase & $\mathrm{KAlSi}_{3} \mathrm{O}_{8}$ & 22.4 & 20.7 & 21.1 & 14.9 & 9.5 & 20.8 & 21.6 \\
\hline Calcite & $\mathrm{CaCO}_{3}$ & 1.7 & 1.5 & 1.0 & 0.0 & 0.0 & 0.6 & 0.0 \\
\hline Pyrite & $\mathrm{FeS}_{2}$ & 0.0 & 0.0 & 0.0 & 0.0 & 0.0 & 0.3 & 0.0 \\
\hline Oligoclase & $(\mathrm{Na}, \mathrm{Ca})\left[\mathrm{Al}(\mathrm{Si}, \mathrm{Al}) \mathrm{Si}_{2} \mathrm{O}_{8}\right]$ & 0.0 & 9.9 & 6.0 & 4.5 & 8.8 & 9.4 & 7.1 \\
\hline Jarosite & $\mathrm{KFe}_{3}\left(\mathrm{SO}_{4}\right)_{2}(\mathrm{OH})_{6}$ & 0.0 & 0.0 & 0.0 & 14.6 & 58.0 & 11.6 & 8.1 \\
\hline Total & & 100.0 & 100.0 & 100.0 & 100.0 & 100.0 & 100.0 & 100.0 \\
\hline
\end{tabular}

Table A2. XRD details for the October 2018 and October 2020 ground surveys. October 2020 soil samples were crushed to a fine powder using a large metal mortar and pestle.

\begin{tabular}{|c|c|c|c|c|c|}
\hline Collection Date & Diffractometer & Detector & Divergence Slit (mm) & $2 \theta$ Start & $2 \theta$ Stop \\
\hline October 2018 & Brukker D2 PHASER XE-T & LYNXEYE XE-T & 0.6 & 5 & 75 \\
\hline October 2020 & Bruker D8 Focus Bragg-Brentano & LYNXEYE - Super Speed Detector & 0.6 & 5 & 75 \\
\hline
\end{tabular}

\section{Appendix B. Maximum Likelihood Confusion Matrices}

We created confusion matrices for the Maximum Likelihood and Spectral Angle Mapper classifications, where columns represent true classes, and rows represent the predictions. All correct classifications are represented along the upper-left to lower-right diagonal. 
Table A3. June 2018 maximum likelihood. Overall accuracy points: 174/200, overall accuracy: 87\%, kappa coefficient: 0.8272 .

\begin{tabular}{cccccc}
\hline Class & EMS & Iron Oxide & Jarosite & Soil & Total \\
\hline Unclassified & 0.00 & 0.00 & 0.00 & 2.74 & 1.00 \\
EMS & 95.12 & 0.00 & 0.00 & 13.70 & 24.50 \\
Iron Oxide & 4.88 & 100.00 & 2.08 & 12.33 & 25.00 \\
Jarosite & 0.00 & 0.00 & 97.92 & 2.74 & 24.50 \\
Soil & 0.00 & 0.00 & 0.00 & 68.49 & 25.00 \\
Total & 100.00 & 100.00 & 100.00 & 100.00 & 100.00 \\
\hline
\end{tabular}

Table A4. September 2018 maximum likelihood. Overall accuracy points: 156/243, overall accuracy: $64 \%$, kappa coefficient: 0.5543 .

\begin{tabular}{cccccc}
\hline Class & Soil & EMS & Jarosite & Iron Oxide & Total \\
\hline Unclassified & 36.89 & 0.00 & 2.94 & 4.44 & 19.75 \\
Soil & 37.70 & 0.00 & 0.00 & 0.00 & 18.93 \\
EMS & 0.00 & 100.00 & 0.00 & 17.78 & 20.58 \\
Jarosite & 13.93 & 0.00 & 97.06 & 0.00 & 20.58 \\
Iron Oxide & 11.48 & 0.00 & 0.00 & 77.78 & 20.16 \\
Total & 100.00 & 100.00 & 100.00 & 100.00 & 100.00 \\
\hline
\end{tabular}

Table A5. November 2018 maximum likelihood. Overall accuracy points: Overall 150/228, overall accuracy: $65 \%$, kappa coefficient: 0.5742 .

\begin{tabular}{cccccc}
\hline Class & EMS & Jarosite & Iron Oxide & Soil & Total \\
\hline Unclassified & 8.16 & 4.55 & 11.11 & 31.48 & 18.86 \\
EMS & 89.80 & 0.00 & 0.00 & 3.70 & 21.05 \\
Jarosite & 0.00 & 95.45 & 0.00 & 7.41 & 21.93 \\
Iron Oxide & 0.00 & 0.00 & 88.89 & 20.37 & 20.18 \\
Soil & 2.04 & 0.00 & 0.00 & 37.04 & 17.98 \\
Total & 100.00 & 100.00 & 100.00 & 100.00 & 100.00 \\
\hline
\end{tabular}

Table A6. March 2019 maximum likelihood. Overall accuracy points: 214/243, overall accuracy: 81\%, kappa coefficient: 0.7723 .

\begin{tabular}{ccccccc}
\hline Class & EMS & AMD & Soil & Jarosite & Iron Oxide & Total \\
\hline Unclassified & 9.09 & 0.00 & 12.66 & 8.16 & 16.98 & 10.27 \\
EMS & 90.91 & 0.00 & 12.66 & 0.00 & 0.00 & 19.01 \\
AMD & 0.00 & 100.00 & 0.00 & 0.00 & 0.00 & 14.45 \\
Soil & 0.00 & 0.00 & 62.03 & 0.00 & 0.00 & 18.63 \\
Jarosite & 0.00 & 0.00 & 6.33 & 89.80 & 1.89 & 19.01 \\
Iron Oxide & 0.00 & 0.00 & 6.33 & 89.80 & 1.89 & 18.63 \\
Total & 100.00 & 100.00 & 100.00 & 100.00 & 100.00 & 100.0 \\
\hline
\end{tabular}

Table A7. July 2019 maximum likelihood. Overall accuracy points: 154/200, overall accuracy: 77\%, kappa coefficient: 0.6933 .

\begin{tabular}{cccccc}
\hline Class & EMS & Jarosite & Iron Oxide & Soil & Total \\
\hline Unclassified & 9.09 & 0.00 & 12.66 & 8.16 & 16.98 \\
EMS & 60.66 & 0.00 & 2.94 & 18.75 & 25.00 \\
Jarosite & 8.20 & 97.56 & 2.94 & 6.25 & 25.00 \\
Iron Oxide & 27.87 & 0.00 & 91.18 & 3.13 & 25.00 \\
Soil & 3.28 & 2.44 & 2.94 & 71.88 & 25.00 \\
Total & 100.00 & 100.00 & 100.00 & 100.00 & 100.00 \\
\hline
\end{tabular}


Table A8. October 2020 maximum likelihood. Overall accuracy points: 122/200, overall accuracy: $61 \%$, kappa coefficient: 0.48 .

\begin{tabular}{cccccc}
\hline Class & Soil & EMS & Iron Oxide & Jarosite & Total \\
\hline Unclassified & 0.00 & 0.00 & 0.00 & 0.00 & 0.00 \\
Soil & 42.74 & 0.00 & 0.00 & 0.00 & 25.00 \\
EMS & 23.93 & 73.91 & 2.56 & 19.05 & 25.00 \\
Iron Oxide & 9.40 & 4.35 & 97.44 & 0.00 & 25.00 \\
Jarosite & 23.93 & 21.74 & 0.00 & 80.95 & 25.00 \\
Total & 100.00 & 100.00 & 100.00 & 100.00 & 100.00 \\
\hline
\end{tabular}

\section{Appendix C. Spectral Angle Mapper Confusion Matrices}

Table A9. June 2018 spectral angle mapper. Overall accuracy points: 110/145, overall accuracy: 75\%, kappa coefficient: 0.6365 .

\begin{tabular}{ccccc}
\hline Class & Jarosite & Iron Oxide & Soil & Total \\
\hline Unclassified & 0.00 & 0.00 & 0.00 & 0.00 \\
Jarosite & 100.00 & 8.00 & 7.23 & 31.03 \\
Iron Oxide & 0.00 & 92.00 & 32.53 & 34.48 \\
Soil & 0.00 & 0.00 & 60.24 & 34.48 \\
Total & 100.00 & 100.00 & 100.00 & 100.00 \\
\hline
\end{tabular}

Table A10. September 2018 spectral angle mapper. Overall accuracy points: 108/147, overall accuracy: 73\%, kappa coefficient: 0.6005 .

\begin{tabular}{ccccc}
\hline Class & Soil & Iron Oxide & Jarosite & Total \\
\hline Unclassified & 0.00 & 0.00 & 0.00 & 0.00 \\
Soil & 56.18 & 0.00 & 0.00 & 34.01 \\
Iron Oxide & 29.21 & 100.00 & 0.00 & 33.33 \\
Jarosite & 14.61 & 0.00 & 100.00 & 32.65 \\
Total & 100.00 & 100.00 & 100.00 & 100.00 \\
\hline
\end{tabular}

Table A11. November 2018 spectral angle mapper. Overall accuracy points: 104/147, overall accuracy: 70\%, kappa coefficient: 0.5595 .

\begin{tabular}{ccccc}
\hline Class & Soil & Iron Oxide & Jarosite & Total \\
\hline Unclassified & 0.00 & 0.00 & 0.00 & 0.00 \\
Soil & 53.76 & 0.00 & 0.00 & 34.01 \\
Iron Oxide & 18.28 & 100.00 & 0.00 & 31.97 \\
Jarosite & 27.96 & 0.00 & 100.00 & 34.01 \\
Total & 100.00 & 100.00 & 100.00 & 100.00 \\
\hline
\end{tabular}

Table A12. March 2019 spectral angle mapper. Overall accuracy points: 119/132, overall accuracy: $90 \%$, kappa coefficient: 0.8502 .

\begin{tabular}{ccccc}
\hline Class & Jarosite & Iron Oxide & Soil & Total \\
\hline Unclassified & 0.00 & 0.00 & 0.00 & 0.00 \\
Jarosite & 97.14 & 2.78 & 1.64 & 27.27 \\
Iron Oxide & 2.86 & 97.22 & 16.39 & 34.85 \\
Soil & 0.00 & 0.00 & 81.97 & 37.88 \\
Total & 100.00 & 100.00 & 100.00 & 100.00 \\
\hline
\end{tabular}


Table A13. July 2019 spectral angle mapper. Overall accuracy points: 134/142, overall accuracy: 94\%, kappa coefficient: 0.9152.

\begin{tabular}{ccccc}
\hline Class & Soil & Iron Oxide & Jarosite & Total \\
\hline Unclassified & 0.00 & 0.00 & 0.00 & 0.00 \\
Soil & 92.59 & 0.00 & 0.00 & 35.21 \\
Iron Oxide & 3.70 & 95.12 & 4.26 & 30.28 \\
Jarosite & 3.70 & 4.88 & 95.74 & 34.51 \\
Total & 100.00 & 100.00 & 100.00 & 100.00 \\
\hline
\end{tabular}

Table A14. October 2020 spectral angle mapper. Overall accuracy points: 117/146, overall accuracy: $80 \%$, kappa coefficient: 0.7009 .

\begin{tabular}{ccccc}
\hline Class & Soil & Iron Oxide & Jarosite & Total \\
\hline Unclassified & 0.00 & 0.00 & 0.00 & 0.00 \\
Soil & 64.94 & 0.00 & 0.00 & 34.25 \\
Iron Oxide & 23.38 & 93.94 & 0.00 & 33.56 \\
Jarosite & 11.69 & 6.06 & 100.00 & 32.19 \\
Total & 100.00 & 100.00 & 100.00 & 100.00 \\
\hline
\end{tabular}

\section{Appendix D. October 2020 XRD Results}
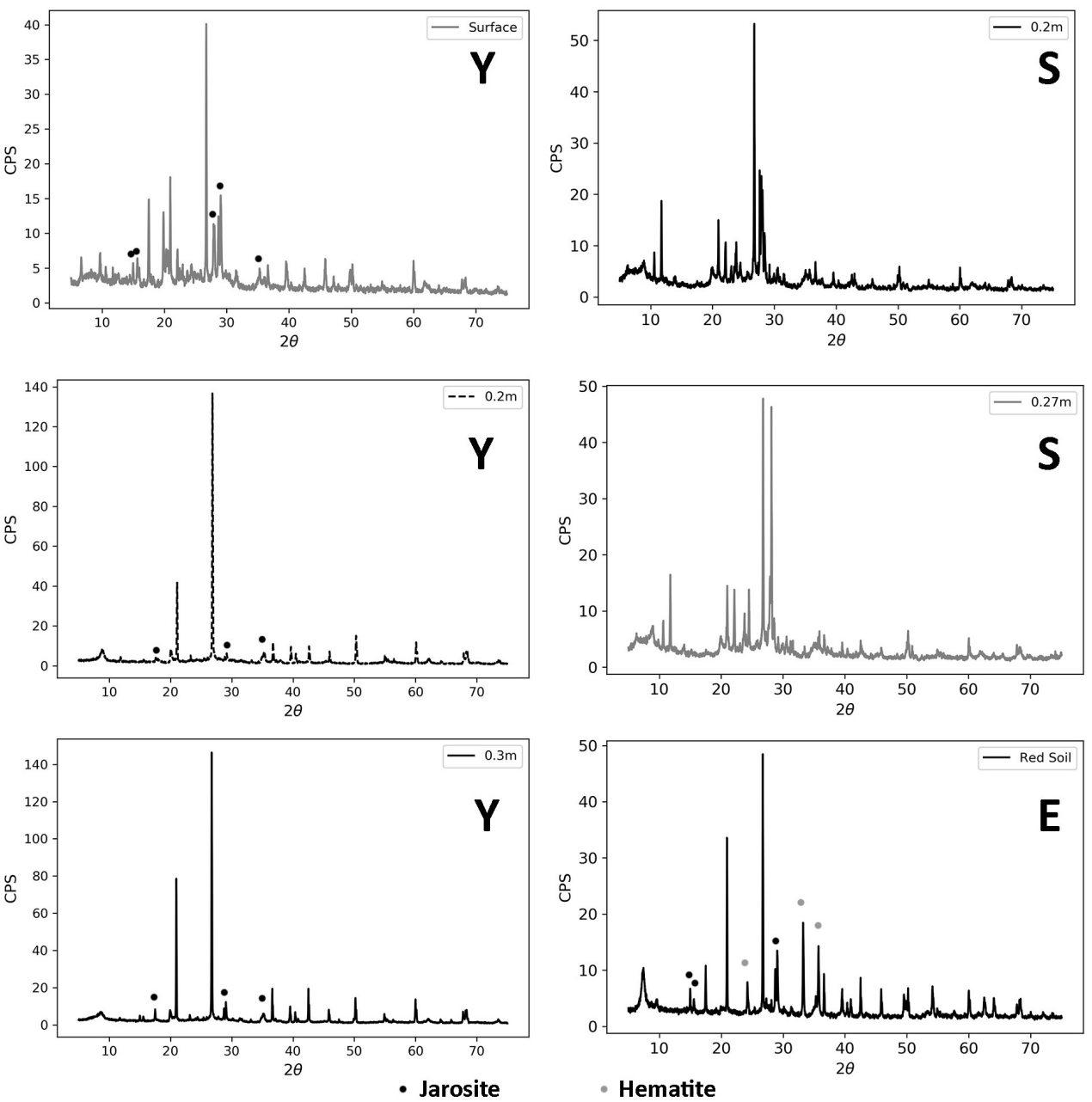

Figure A1. Results of XRD October 2020. Jarosite peaks in Y and E, indicated using a black dot, have weak peaks in the $2 \theta$ values of $14.9,15.5,28.6,29$, and $35.3^{\circ}$. Hematite peaks in E, indicated using a gray dot, have weak peaks in the $2 \theta$ values of $24.2,33.2$, and $35.7^{\circ}$, and quartz has strong peaks in the $2 \theta$ values of $2.8,26.6$, and $36.5^{\circ}$ in all samples. 


\section{References}

1. Plumlee, G.; Logsdon, M.; Filipek, L. The Environmental Geochemistry of Mineral Deposits: Part A: Processes, Techniques, and Health Issues Part B: Case Studies and Research Topics. Soc. Econ. Geol. 1997, 6, 583. [CrossRef]

2. Alpers, C.; Blowes, D.; Nordstrom, D.; Jambor, J. Secondary minerals and acid mine-water chemistry. In The Environmental Geochemistry of Sulfide Mine-Wastes; Blowes, D., Jambor, J., Eds.; Mineralogical Association of Canada: Quebec, QC, USA, 1994; Volume 22, Chapter 9, pp. 246-270.

3. Macmillan, F.; Bradley, B.; Ghose, S.; Doolan, M.; Bishop, M.; Cohn, M.; Russ, C.; Dunn, J.; Evans, E.; Fliniau, H.; et al. Abandoned Mine Site Characterization and Cleanup Handbook; Technical Report; Environmental Protection Agency: Washington, DC, USA, 2000.

4. Albright, W.H.; Benson, C.H.; Waugh, W.J. Water Balance Covers for Waste Containment: Principles and Practice, 5th ed.; American Society of Civil Engineering: Reston, VA, USA, 2010. [CrossRef]

5. Hauser, V.L. Evapotranspiration Covers for Landfills and Waste Sites, 1st ed.; CRC Press: Boca Raton, FL, USA, 2008.

6. Hutchinson, I.; Ellison, R. Mine Waste Management Requirements, 1st ed.; Lewis Publishers: Chelsea, MI, USA, $1992 ;$ Volume 24.

7. Johnson, D.B.; Hallberg, K.B. Acid mine drainage remediation options: A review. Sci. Total Environ. 2005, 338, 3-14. [CrossRef]

8. Song, L.; Jian, J.; Tan, D.J.; Xie, H.B.; Luo, Z.F.; Gao, B. Estimate of heavy metals in soil and streams using combined geochemistry and field spectroscopy in Wan-sheng mining area, Chongqing, China. Int. J. Appl. Earth Observ. Geoinf. 2015, 34, 1-9. [CrossRef]

9. Ghiglieri, R. Nevada Abandoned Mine Lands Physical Hazards Report; Technical Report; Nevada Division of Minerals: Carson City, NV, USA, 2019.

10. USFS; BLM. Abandoned Mine Lands: A Decade of Progress Reclaiming Hardrock Mines; Technical Report FS-891, BLM-WO-GI-07-0133720; United States Forest Service and Bureau of Land Management: Washington, DC, USA, 2007.

11. Esposito, G.; Mastrorocco, G.; Salvini, R.; Oliveti, M.; Starita, P. Application of UAV photogrammetry for the multi-temporal estimation of surface extent and volumetric excavation in the Sa Pigada Bianca open-pit mine, Sardinia, Italy. Environ. Earth Sci. 2017, 76, 103. [CrossRef]

12. Xiang, J.; Chen, J.; Sofia, G.; Tian, Y.; Tarolli, P. Open-pit mine geomorphic changes analysis using multi-temporal UAV survey. Environ. Earth Sci. 2018, 77, 220. [CrossRef]

13. Notesco, G.; Kopačková, V.; Rojík, P.; Schwartz, G.; Livne, I.; Dor, E. Mineral Classification of Land Surface Using Multispectral LWIR and Hyperspectral SWIR Remote-Sensing Data. A Case Study over the Sokolov Lignite Open-Pit Mines, the Czech Republic. Remote Sens. 2014, 6, 7005-7025. [CrossRef]

14. Davies, G.E.; Calvin, W.M. Quantifying Iron Concentration in Local and Synthetic Acid Mine Drainage: A New Technique Using Handheld Field Spectrometers. Mine Water Environ. 2017, 36, 299-309. [CrossRef]

15. Davies, G.E.; Calvin, W.M. Mapping acidic mine waste with seasonal airborne hyperspectral imagery at varying spatial scales. Environ. Earth Sci. 2017, 76, 432. [CrossRef]

16. Swayze, G.A.; Smith, K.S.; Clark, R.N.; Sutley, S.J.; Pearson, R.M.; Vance, J.S.; Hageman, P.L.; Briggs, P.H.; Meier, A.L.; Singleton, M.J.; et al. Using Imaging Spectroscopy To Map Acidic Mine Waste. Environ. Sci. Technol. 2000, 34, 47-54. [CrossRef]

17. MWH; Program, U.A.C.O.E.R.; BLM. Final Perry Canyon Site Investigation Report Usace Contract No. DACW45-03-D-0001; Final Investigation Site Characterization; Bureau of Land Management: Reno, NV, USA, 2006.

18. BLM. Mine Adit Closures, Perry Canyon, Washoe County, Nevada; Statement of Work; Bureau of Land Management: Reno, NV, USA, 2006.

19. Horton, J.; San Juan, C. Prospect- and Mine-Related Features from U.S. Geological Survey 7.5- and 15-Minute Topographic Quadrangle Maps of the United States; Series: Data Series; United States Geological Survey: Reston, VA, USA, 2006. [CrossRef]

20. Cramer, A.; McCoy, S.; Breitmeyer, R. Change Detection on Abandoned Mine Lands Using Unmanned Aerial Systems. In Proceedings of the 2019 Fall Meeting, AGU, San Francisco, CA, USA, 9-13 December 2020.

21. Breitmeyer, R.J.; Stewart, M.K.; Huntington, J.L. Evaluation of Gridded Meteorological Data for Calculating Water Balance Cover Storage Requirements. Vadose Zone J. 2018, 17, 180009. [CrossRef]

22. Ruehl, M.D.; Hiibel, S.R. Evaluation of organic carbon and microbial inoculum for bioremediation of acid mine drainage. Miner. Eng. 2020, 157, 106554. [CrossRef]

23. Price, J.G.; Shevenell, L.; Henry, C.D.; Rigby, J.G.; Christensen, L.G.; Desilets, M.O.; Fields, R.; Driesner, D.; Durbin, B.; Lombardo, W. Nevada Bureau of Mines and Geology Open-File Report 95-4 for the Western Governors' Association; Technical Report; Nevada Bureau of Mines and Geology: Reno, NV, USA, 1995.

24. BLM; Golden Crescent, Consulting. Perry Canyon Acid Mine Drainage Rehabilitation CX No. NV-030; Categorical Exclusion Environmental Review and Approval; Bureau of Land Management: Reno, NV, USA, 2006.

25. Neumann, T. Perry Canyon Mine Adit Closures Report; Closure Report; Bureau of Land Management: Reno, NV, USA, 2006.

26. Hammarstrom, J.; Seal, R.; Meier, A.; Kornfeld, J. Secondary sulfate minerals associated with acid drainage in the eastern US: Recycling of metals and acidity in surficial environments. Chem. Geol. 2005, 215, 407-431. [CrossRef]

27. Alpers, C.N.; Nordstrom, D.; Ball, J.W. Solubility of jarosite solid solutions precipitated from acid mine waters, Iron Mountain, California, USA. Sci. Géol. Bull. 1989, 42, 281-298. [CrossRef]

28. Schaider, L.A.; Senn, D.B.; Estes, E.R.; Brabander, D.J.; Shine, J.P. Sources and fates of heavy metals in a mining-impacted stream: Temporal variability and the role of iron oxides. Sci. Total Environ. 2014, 490, 456-466. [CrossRef]

29. Plumlee, G.S. The Environmental Geology of Mineral Deposits; Society of Economic Geologists: Littleton, CO, USA, 1999 ; p. 46. 
30. Cloutis, E.; Hawthorne, F.; Mertzman, S.; Krenn, K.; Craig, M.; Marcino, D.; Methot, M.; Strong, J.; Mustard, J.; Blaney, D. Detection and discrimination of sulfate minerals using reflectance spectroscopy. Icarus 2006, 184, 121-157. [CrossRef]

31. Kokaly, R.; Clark, R.N.; Swayze, G.A.; Livo, K.; Hoefen, T.; Pearson, N.; Wise, R.; Benzel, W.; Lowers, H.; Driscoll, R.; et al. USGS Spectral Library Version 7; Series: Data Series; United States Geological Survey: Reston, VA, USA, 2017.

32. PIX4D. Manual-Support. 2011. Available online: https://support.pix4d.com/hc/en-us/sections/360003718992-Manual (accessed on 1 January 2021).

33. Westoby, M.; Brasington, J.; Glasser, N.; Hambrey, M.; Reynolds, J. ‘Structure-from-Motion' photogrammetry: A low-cost, effective tool for geoscience applications. Geomorphology 2012, 179, 300-314. [CrossRef]

34. Alcala, J.M.L.; Haagsma, M.; Udell, C.J.; Selker, J.S. HyperRail: Modular, 3D printed, 1-100 m, programmable, and low-cost linear motion control system for imaging and sensor suites. HardwareX 2019, 6, e00081. [CrossRef]

35. Smith, G.M.; Milton, E.J. The use of the empirical line method to calibrate remotely sensed data to reflectance. Int. J. Remote Sens. 1999, 20, 2653-2662. [CrossRef]

36. Richards, J.A. Remote Sensing Digital Image Analysis, 5th ed.; Springer: Berlin/Heidelberg, Germany, 1999. [CrossRef]

37. Kruse, F.A.; Heidebrecht, K.B.; Shapiro, A.T.; Barloon, P.J.; Goetz, A.F.H. The Spectral Image Processing System (SIPS) Interactive Visualization and Analysis of Imaging Spectrometer Data. Remote Sens. Environ. 1993, 44, 145-163. [CrossRef]

38. Gražulis, S.; Chateigner, D.; Downs, R.T.; Yokochi, A.F.T.; Quirós, M.; Lutterotti, L.; Manakova, E.; Butkus, J.; Moeck, P.; Le Bail, A. International Union of Crystallogaphy CrossMark Policy Statement; Type: Dataset, Technical Report; International Union of Crystallography: Chester, UK, 2009. [CrossRef]

39. Wang, A.; Ling, Z.C. Ferric sulfates on Mars: A combined mission data analysis of salty soils at Gusev crater and laboratory experimental investigations. J. Geophys. Res. 2011, 116, E00F17. [CrossRef]

40. Derun, E.M.; Tugrul, N.; Senberber, F.T.; Kipcak, A.S.; Piskin, S. The Optimization of Copper Sulfate and Tincalconite Molar Ratios on the Hydrothermal Synthesis of Copper Borates. World Acad. Sci. Eng. Technol. Int. J. Chem. Mol. Eng. 2014, 8, $1152-1156$. 